\title{
LOS PROCESOS DE MOSCÚ: MENTIRA Y PROPAGANDA. EL CASO TROTSKY DESDE LA PERSPECTIVA DE LA COMISIÓN DEWEY*
}

\author{
Diego Antonio Pineda Rivera* \\ doi: 10.11144/Javeriana.uph36-72.pmcd
}

\begin{abstract}
RESUMEN
Este artículo examina un caso específico de mentira, a la vez judicial y mediática, propiciada desde las altas esferas del poder político: el caso León Trotsky, desde la perspectiva del trabajo que hizo la Comisión Internacional de Investigación presidida por el filósofo norteamericano John Dewey. Después de una justificación y contextualización general del tema, y de un recuento histórico de los acontecimientos que rodearon los "Procesos de Moscú" y la constitución de la Comisión Dewey, se da cuenta de algunas de las razones por las cuales dicha comisión estableció que tales procesos habían sido montajes judiciales. Se concluye con una referencia al modo como Dewey denunció posteriormente la falsificación mediática de estos acontecimientos a través del libro (y la película) Misión en Moscú.
\end{abstract}

Palabras clave: León Trotsky; Comisión Dewey; Procesos de Moscú; totalitarismo; montaje judicial

\footnotetext{
El presente trabajo es fruto del semestre sabático que la Pontificia Universidad Javeriana le concedió a su autor durante el segundo semestre del año 2018.

*. Pontificia Universidad Javeriana, Bogotá, Colombia.

Correo electrónico: diegopi@javeriana.edu.co

Para citar este artículo: Pineda Rivera, D. A. (2019). Los procesos de Moscú: mentira y propaganda. El caso Trotsky desde la perspectiva de la Comisión Dewey. Universitas Philosophica, 36(72), 173-217. ISSN 0120-5323, ISSN en línea 2346-2426. doi: 10.11144/Javeriana.uph36-72.pmcd
} 


\title{
THE MOSCOW TRIALS: LIE AND PROPAGANDA. THE TROTSKY CASE FROM THE PERSPECTIVE OF THE DEWEY COMMISSION
}

\begin{abstract}
This article examines a specific case of lying, at the same time judicial and mediatic, promoted from the highest levels of political power, the Leon Trotsky case, from the perspective of the work done by the International Commission of Investigation chaired by the American philosopher John Dewey. After a general justification and contextualization of the subject, and a historical account of the events that surrounded the "Moscow Trials" and the constitution of the Dewey Commission, some of the reasons why the commission concluded that such processes had been judicial assemblies are reported. It closes with a reference to the way Dewey later denounced the media falsification of these events through the book (and the film) Mission to Moscow.
\end{abstract}

Keywords: Leon Trotsky; Dewey Commission; Moscow Trials; totalitarianism; judicial frame-up 
Hay fronteras claramente establecidas entre la devoción por la justicia y la adhesión a una facción, entre el juego limpio y el amor por la oscuridad, que es algo efectivamente reaccionario, no importa la bandera que enarbole. Actuamos en nombre de la justicia y de la verdad como los fines en que buscamos soporte. Tenemos confianza en que ellas llegarán. Como dijo Zola en el caso Dreyfus, "la verdad está en marcha y ya nada la detendrá". John Dewey, 9 de mayo de $1937^{1}$

Aunque habia sido critico del programa politico de la Unión Soviética bajo el dominio de Stalin, nunca sospeché que el régimen soviético estuviese dispuesto a violar todas esas normas fundamentales de decencia a partir de las cuales se ha conformado la textura de la vida civilizada. Los procesos de Moscú me enseñaron que cualquier concepción del socialismo que rechace la centralidad de los valores morales resulta siendo solamente un disfraz ideológico para el totalitarismo. Sidney Hook, "Recuerdos de los procesos de Moscú"

EN EL PRESENTE ESCRITO, que se ofrece como una contribución a investigaciones más amplias ${ }^{2}$, me propongo presentar un caso -el de la persecución de la

1 De un discurso, pronunciado en el Mecca Temple de Nueva York, después de haber presentado el informe de la subcomisión que viajó a México a tomar la declaración de Trotsky. El texto del discurso circuló luego como un panfleto de quince páginas del Comité Norteamericano para la Defensa de León Trotsky bajo el título "Truth Is on the March", o "La verdad está en marcha”.

2 Se trata de una contribución a dos investigaciones distintas: por una parte, al proyecto "Mentira, poder estatal y democracia”, desarrollado por varios profesores de la Facultad de Filosofía de la Pontificia Universidad Javeriana y cuyo investigador principal es Juan Samuel Santos; por otra, es parte de una investigación más amplia sobre la participación que tuvo el filósofo norteamericano John Dewey, como presidente de la Comisión Internacional de Investigación que examinó los cargos hechos contra León Trotsky y su hijo en los procesos de Moscú. Esta última tarea implica tanto la traducción de los diversos textos que sobre el caso Trotsky escribió Dewey (entre ellos el informe de la Comisión conocido como Not Guilty) como la elaboración de un ensayo sobre algunos problemas filosóficos implicados en la relación que tuvieron estos dos intelectuales, Dewey y Trotsky, y que incluye reflexiones sobre la lógica de la investigación, los derechos políticos de los individuos, la relación entre fines y medios en la vida moral y política, las relaciones existentes entre marxismo y pragmatismo, etc. Lo que aquí ofrezco, como lo advertiré un poco más adelante, es una presentación general de los hechos que rodearon el caso Trotsky como un caso específico de una mentira, a la vez judicial y mediática, montada desde las altas esferas del poder estatal y la intervención que en este asunto tuvo John Dewey, como una muestra de la defensa de la verdad desde la perspectiva de un liberalismo democrático. 
dictadura estalinista contra el dirigente soviético León Trotsky- en que el poder de un Estado constituido y poderoso - nada menos que uno de los mayores aparatos políticos, militares y de propaganda de que tengamos noticia: la burocracia de la época soviética- hace de la mentira, tanto judicial como mediática, la estrategia por excelencia para eliminar a sus contradictores políticos.

En el año 2017 se cumplieron cien años de la Revolución Bolchevique y ochenta de un acontecimiento que, aunque parezca menor, resulta de una inmensa relevancia para todos los que estamos convencidos de que el establecimiento de la verdad histórica es una condición indispensable para la construcción de una paz duradera: el examen que hizo la subcomisión presidida por el filósofo norteamericano John Dewey, en Coyoacán, Ciudad de México, de las acusaciones elevadas en los procesos de Moscú (Moscow Trials) por el régimen de Stalin en contra de León Trotsky -a quien muchos consideraban el sucesor natural de Lenin, no solo por su reconocida capacidad intelectual, sino por el rol que había cumplido en el naciente Estado soviético y, especialmente, por su papel como Comandante del Ejército Rojo durante la guerra civil que siguió a la revolución-.

Como lo sugirió en su momento Karl Kraus (1990, pp. 17-22), la inmoralidad que provoca escándalo público, lejos de provenir de la vida privada de los individuos, tiene su origen en el tratamiento judicial y en la exposición mediática de los asuntos personales y las diferencias ideológicas. La mentira fabricada contra Trotsky por parte del régimen estalinista tuvo esta doble dimensión: por una parte, la del montaje judicial que, a través de confesiones forzadas, condujo a la condena y aniquilación de los principales protagonistas de la revolución bolchevique; por otra, la de la propaganda mediática que, apoyada en la naciente industria de Hollywood, creó versiones de los hechos favorables al régimen político de turno. Los dos aspectos del asunto hicieron parte de una misma estrategia de ocultación y falseamiento, estrategia que logró hacer pasar una mentira tanto más exagerada como una verdad tanto más creíble. Hoy en día, en efecto, parece inverosímil que Trotsky, uno de los líderes por excelencia de la Revolución Bolchevique, pereciera bajo la sospecha de haberse aliado con el nazismo alemán para restablecer el capitalismo en la Unión Soviética.

El poder estatal tomó en este caso su forma más sombría: la de una lucha ideológica en el interior del Partido marcada por alianzas, traiciones y componendas y -peor aún- la del montaje de un aparato judicial basado en la delación, la 
incriminación mutua, las confesiones forzadas y los procedimientos extrajudiciales propios de un Estado totalitario. La democracia, mientras tanto, brillaba por su ausencia, pues todo ocurría en los albores de la Segunda Guerra Mundial, cuando la Alemania de Hitler, la Italia de Mussolini y la Unión Soviética de Stalin ya se habían consolidado como importantes poderes económicos, políticos y militares. Los demás Estados europeos, por su parte, se cuidaban al máximo de intervenciones o pronunciamientos políticos que los pudieran envolver en los peligrosos juegos de poder que más tarde probarían su capacidad destructiva. Los gestos democráticos llegaron, sin embargo, del otro lado del Atlántico: del Estado mexicano y unos pocos intelectuales de ese país y de los comités de defensa organizados por ciudadanos independientes en los Estados Unidos.

Antes de entrar al relato detallado de esta historia, tal vez sea necesario explicar la importancia actual de un asunto tan lejano en el tiempo y el espacio, que ocurrió en la Unión Soviética hace más de ochenta años, del que fueron protagonistas uno de los líderes de la Revolución de Octubre y el filósofo y educador más representativo del liberalismo norteamericano, separados por miles de kilómetros, en orillas opuestas del océano. Debo advertir, sin embargo, que no podré abordar algunos de los aspectos más complejos de este acontecimiento, no solo por el poco espacio del que dispongo, sino porque este escrito tiene un carácter básicamente descriptivo. Tampoco entraré en las consideraciones filosóficas que podrían surgir de este asunto; y ello no solo porque implicarían otro tipo de escrito, que seguramente elaboraré en un momento más avanzado de mi investigación, sino porque los acontecimientos mismos que rodearon los juicios a Trotsky (tanto los que se hicieron sin su presencia en Moscú como las audiencias que presidió Dewey en Ciudad de México) no son suficientemente conocidos entre el público filosófico del mundo de habla hispana y muchas veces han sido ocultados de forma deliberada, o al menos falseados, para responder a oscuros intereses políticos.

\section{1. ¿ Por qué Trotsky y Dewey, ochenta años después?}

¿Por Qué elegir el caso Trotsky? Se trata, sin duda, de un caso paradigmático, no solo como un ejemplo relevante de fabricación de la verdad desde las altas esferas del poder político, sino como una tragedia política, una historia 
emblemática de cómo un Estado poderoso puede ensañarse contra una persona ${ }^{3}$. Lo que ocurrió en los años treinta del siglo XX en la Unión Soviética (las purgas en el interior del Partido Comunista, los procesos de Moscú y, de modo particular, la brutal persecución contra Trotsky y toda su familia, que condujo a su casi total aniquilación $n^{4}$ ) ha quedado, sin embargo, por muchos años casi en el olvido. A diferencia de lo que ocurrió con la barbarie nazi, que ha sido objeto de todo tipo de investigación y difusión, los horrores del estalinismo, aunque fueron reconocidos por el sucesor de Stalin en 1956 y denunciados y documentados por algunos autores en los años ochenta y noventa del siglo pasado, nunca fueron objeto de un juicio histórico que permitiera establecer más claramente la verdad sobre lo ocurrido en la Rusia soviética desde finales de los años veinte y hasta bien entrados los cincuenta; y muchos de esos crímenes, aún hoy, casi treinta años después de la caída del régimen soviético, siguen sin ser suficientemente investigados y son todavía poco conocidos en buena parte del mundo occidental.

Estamos lejos de contar con una denuncia y una investigación más o menos completas de la barbarie estalinista. Solo recientemente el caso Trotsky, aunque no la totalidad de los crímenes del estalinismo, ha recobrado alguna relevancia pública a través de la reconstrucción literaria que de su asesinato han hecho novelistas como Leonardo Padura (2009) y John Davidson (2016)5. Es muy probable

3 Sobre Trotsky como personaje trágico, véase Steiner, 2003.

4 Cabe recordar que no solo Trotsky fue objeto de una implacable persecución por parte del estalinismo. Lo fueron también sus hijos, e incluso otros familiares y amigos cercanos a él. Trotsky tuvo dos esposas y cuatro hijos. Su primera esposa, Alexandra Sokolovskaya, fue deportada a Siberia, donde murió en 1938. Su hija mayor, Zinaida, se suicidó en Berlín, en 1933, después de sufrir terribles enfermedades y persecuciones; la segunda, Nina, murió de tuberculosis en 1928. También los dos yernos de Trotsky fueron asesinados por el régimen soviético en las purgas de los años treinta. Luego tuvo dos hijos, de su segundo matrimonio, con Natalia Sedova. El mayor, León Sedov, fue condenado, junto con él, en los procesos de Moscú; desarrollaba una importante actividad política y literaria en París, donde murió misteriosamente después de una operación de apendicitis (todo indica que fue envenenado por agentes soviéticos). El menor de todos, Sergei, se encontraba completamente alejado de la política y se dedicaba a enseñar matemáticas en una escuela técnica de la URSS; sin embargo, fue arrestado en 1934, condenado a trabajos forzados y finalmente fusilado en 1937. La lista de los amigos de Trotsky que fueron ejecutados por el régimen es también bastante larga.

5 La novela de Padura, El hombre que amaba los perros, ampliamente conocida en el mundo de habla hispana y objeto de múltiples reconocimientos, reconstruye de forma maravillosa todos los sucesos 
que todos estos crímenes -y fueron muchos- queden por completo en la impunidad y el olvido, pues no habrá ya algo semejante a los juicios de Núremberg o comisiones de la verdad que los saquen a flote. Pero no puede quedar oculta la estrategia que convirtió una mentira tan grande en verdad indubitable.

De todo este proceso quedaron pocos recuerdos, pues inmediatamente sobrevino la Segunda Guerra Mundial, y especialmente porque la barbarie nazi terminó por ocultar este y muchos otros de los más horribles crímenes del estalinismo. Puesto que la Unión Soviética estuvo entre los vencedores de la guerra, estos crímenes solo empezaron a revelarse, y de forma muy tenue, tras la muerte de Stalin; pero muy pronto se impuso nuevamente un marcado silencio. Hoy, de diversos modos, se viene reivindicando la memoria de Trotsky como el hombre que se opuso de forma decidida a la barbarie estalinista, y estos sucesos vuelven a cobrar importancia, no solo por la relevancia histórica del personaje en mención, sino sobre todo porque constituye uno de los casos paradigmáticos de una mentira política y judicial propiciada y ejecutada desde las altas esferas del poder estatal de una de las más importantes potencias del mundo.

Hay, sin embargo, una dimensión de este asunto que puede resultar particularmente relevante para aquellos países, como la Colombia del posacuerdo, en los que el establecimiento de la verdad histórica es un componente esencial de la construcción de una paz estable y duradera: se trata de una indagación (evito, para empezar, el uso de términos más precisos como "juicio" "investigación", etc., que tienen un tono más específicamente jurídico), de la que vino a conocerse como la Comisión Dewey, en donde lo esencial no era determinar si alguien era culpable o inocente (de hecho, Trotsky y su hijo habían sido ya declarados

que rodearon el asesinato de Trotsky por parte de Ramón Mercader, valiéndose del hecho de que este último vivió los últimos años de su vida en la isla de Cuba. La novela de Davidson, El asesino obediente, reconstruye el mismo asunto, pero desde una perspectiva diferente: el modo como Mercader se infiltró en el círculo íntimo de Trotsky, a través de su relación con la militante trotskista Sylvia Ageloff, para lograr dar muerte a Trotsky. Han surgido muchos otros escritos en los últimos tiempos sobre la persecución a Trotsky y su asesinato, así como sobre Ramón Mercader y su familia, y especialmente la compleja relación que este tuvo con su madre: Caridad del Río. Destaco entre ellos el ensayo El cielo prometido: una mujer al servicio de Stalin, escrito por el filósofo español Gregorio Luri (2016), en donde hace una interesante reconstrucción de los antecedentes familiares y políticos de Ramón Mercader y su madre e intenta esclarecer el ambiente en que se gestó la vida de estos servidores del estalinismo, encargados de dar muerte a Trotsky. 
culpables en los procesos de Moscú), sino de establecer la verdad de lo ocurrido y, por tanto, de determinar si resultaban o no sostenibles, a la luz de la evidencia recogida, las acusaciones que se habían hecho contra una persona a la que se le había negado el legítimo derecho a la defensa.

En cierto sentido, la Comisión Dewey era una especie de comisión de la verdad, aunque con componentes muy distintos a las que muchos años después se establecerían en países como Sudáfrica, Irlanda y la propia Colombia. Estaba centrada en una sola persona (y no en el esclarecimiento de los delitos atroces ocurridos en el marco de una guerra recientemente superada); deliberó por un tiempo muy corto (ocho días) y entregó muy pronto su informe; y, sobre todo, tuvo resonancia internacional, pues en ella participaron personalidades de muy distintas nacionalidades, ideologías y profesiones. Lo que ocurrió en Coyoacán en abril de 1937 fue en cierto modo extraordinario, pues se trataba de examinar la validez de unos procesos judiciales ocurridos a miles de kilómetros de allí, en los que estaban involucrados muy diversos personajes (la gran mayoría desconocidos para los presentes y muchísimos de ellos ya muertos o ejecutados). Se buscaba determinar si eran válidas las acusaciones proferidas por el dirigente máximo de una de las grandes potencias del mundo contra uno de los mayores líderes de una revolución triunfante, la primera revolución proletaria de la historia. En la Comisión obraban como jueces individuos que pertenecían a otras muy diversas naciones, entre ellas la otra gran potencia del mundo, Estados Unidos, y tuvo lugar en un país latinoamericano, México, único Estado que dio asilo a Trotsky, venciendo las prevenciones que motivaron el rechazo de todos los demás gobiernos del mundo a los que el exiliado había acudido, y que prefirieron no comprometerse con quien era considerado por las autoridades soviéticas como el mayor enemigo del comunismo internacional, aliado del fascismo y traidor a la patria.

Afortunadamente, toda acción del poder estatal genera algún tipo de resistencia. En este caso, la resistencia contra el estalinismo vino de un reducido grupo de ciudadanos, especialmente norteamericanos, que se organizaron en comités de defensa para garantizar que el derecho al asilo y a no ser condenado sin haber ejercido su legítimo derecho a la defensa se cumpliese en el caso de Trotsky. Al frente de estos comités de defensa estaba un filósofo y educador que había hecho de su vida un compromiso radical con los principios democráticos: John Dewey. A él le correspondería personalmente tomar el testimonio de Trotsky y 
conducir el proceso investigativo que llevó a la determinación de su inocencia y a la denuncia de los procesos moscovitas como simples montajes judiciales. Para comprender cómo y por qué dos personajes tan distintos, dos intelectuales de tendencias tan diversas, un revolucionario soviético y un liberal norteamericano, llegaron a encontrarse -el uno en condición de testigo y el otro en condición de presidente de una comisión de investigación-, será preciso recordar brevemente algunos acontecimientos históricos.

\section{Breve recuento de los acontecimientos históricos que rodearon los procesos de Moscú}

TRAS LA MUERTE De Lenin en enero de 1924 y el ascenso al poder del dictador Joseph Stalin, Trotsky fue objeto de una severa persecución por parte del Estado soviético, que empezó por su expulsión del Partido Comunista (1927) y luego del territorio de la Unión Soviética (1929), tras lo cual vivió exiliado por muchos años en países como Turquía, Francia y Noruega. En los llamados procesos de Moscú, ocurridos entre 1936 y 1938, fue juzgado en ausencia bajo acusaciones de sabotaje, terrorismo, conspiración con el nazismo, entre otras, y declarado culpable sin que se le hubiera permitido ejercer su defensa; su persecución concluyó, finalmente, con su asesinato en Ciudad de México en agosto de 1940.

Una de las principales herramientas de la persecución del estalinismo contra uno de los principales líderes de la revolución fueron estos procesos, en los que también se acusó de diversos crímenes a los más reconocidos dirigentes de la Revolución Bolchevique y líderes militares durante la Guerra Civil, muchos de ellos cercanos a Trotsky, aunque no necesariamente sus seguidores. Todos ellos, después de juicios amañados, basados en sospechosas "confesiones" y en ausencia de toda prueba material, fueron condenados y posteriormente fusilados. Aunque para esa época Trotsky llevaba ya varios años en el exilio, era, desde luego, el principal acusado y fue, por tanto, juzgado en ausencia y sin que se le permitiera, bajo ninguna circunstancia, ejercer su derecho a la defensa. La acusación, además, se extendió a uno de los miembros de su familia: su hijo León Sedov.

¿Pero qué fueron los procesos de Moscú? Estos incluyeron al menos cuatro juicios que George Novack (2010) resume con precisión en su introducción a la edición de 1969 de las audiencias de la "Comisión Dewey" en Coyoacán: 
Sus secuaces [los de Stalin] montaron cuatro juicios clave entre 1936 y 1938. El primero fue "el juicio de los dieciséis", con Zinoviev, Kamenev, Smirnov, Mrachkovsky y otros como acusados; el segundo, "el juicio de los diecisiete", que incluía a Pyatakov, Radek, Sokolnikov, Muralov, Serebryakov y otros, tuvo lugar en enero de 1937. Luego siguió el juicio secreto al Mariscal Tujachevsky y un grupo de generales de alto rango del Ejército Rojo en junio de 1937; y, finalmente, "el juicio de los veintiuno" (Rykov, Bujarin, Krestinsky, Rakovsky, Yagoda y otros) en marzo de 1938.

Los hombres en el banquillo incluían a todos los miembros del Politburó de Lenin, excepto el mismo Stalin. Trotsky, a pesar de su ausencia, fue el principal acusado en esos procesos. Él y la vieja guardia bolchevique estaban acusados de complotar para asesinar a Stalin y otros dirigentes soviéticos, de conspirar para desbaratar el poder económico y militar del país y de matar a masas de trabajadores rusos. También fueron acusados de trabajar, desde los primeros días de la Revolución Rusa, para los servicios de espionaje de Gran Bretaña, Francia, Japón y Alemania y de hacer acuerdos secretos con agentes de Hitler y el Mikado, con el objetivo de ceder vastas porciones del territorio soviético a los imperialismos alemán y japonés. Los acusados en Moscú confesaron abyectamente su culpabilidad; solo Trotsky no lo hizo.

Los juicios de estos notables fueron acompañados y seguidos de una purga espantosa de personas de todas las esferas de la vida soviética [...]. Aún no se sabe cuántos fueron atrapados en esta red sangrienta, ya que los regímenes postestalinistas aún se niegan a divulgar los hechos. Pero el número rondaba los millones (pp. 29-30).

No resulta fácilmente comprensible lo que ocurría por aquellos años en la Unión Soviética para quienes estamos situados más de ochenta años después de los acontecimientos, y sobre todo por qué razones y en qué contexto se montó una trama judicial como esta. Uno de los que mejor conocieron este asunto, tanto por su cercanía personal con John Dewey como por su amplio conocimiento del marxismo y de las luchas políticas de aquellos tiempos, fue el filósofo norteamericano Sidney Hook (1984), quien, en sus "Recuerdos de los procesos de Moscú", nos pone de presente el clima de opinión que había por aquellos años entre los intelectuales norteamericanos y el significativo cambio que se dio en el 
movimiento comunista oficial a partir del Séptimo Congreso de la Internacional Comunista de 1935, pues allí se determinó que los movimientos comunistas debían ahora desarrollar lo que entonces se llamó una política de "frente popular" en la cual se deberían admitir alianzas con otros grupos políticos siempre y cuando se emprendiese con tales grupos una defensa a ultranza de la Unión Soviética. Dejemos que sea Hook (1984) el que nos lo relate en sus propios términos:

A partir de un extremismo revolucionario atolondrado, en el cual incluso el ala de izquierda de los socialdemócratas - por no decir nada de los liberales- habían sido denunciados como aliados del fascismo, la Internacional Comunista ahora giraba en la dirección de una política en que se aliaba con cualquier grupo que estuviese dispuesto a constituirse en un frente popular cuyo principio fundamental fuese la defensa de la Unión Soviética. Este giro fue bienvenido por casi todos los grupos liberales al tiempo, principalmente a causa de que ello significaba el cese de la previa, dura y constante artillería verbal de denuncias contra los reformistas por parte de los múltiples órganos de la propaganda comunista. [...].

Desde el punto de vista psicológico, esta transición abrupta desde lo que se llamaba, en una expresión técnica, "extremismo del tercer periodo" hacia una política de frente popular estimuló la abierta adhesión de un considerable número de intelectuales, académicos y profesionales a causas organizadas o dominadas por los comunistas. En los años anteriores una adhesión pública de ese tipo acarreaba algún riesgo, dado que implicaba la colaboración con un partido que luchaba abiertamente por la toma del poder por medio de la fuerza y la violencia. Ahora, en cambio, no había riesgo alguno. Y ello porque, en un esfuerzo tardío por dejar establecida su legitimidad como un partido político nativamente norteamericano, los comunistas estaban ahora citando a Jefferson y a Lincoln más que a Marx y a Lenin. [...].

En el escenario internacional, el cambio era aún más dramático. Incluso después de que Hitler hubiese llegado al poder, el Kremlin seguía justificando la política que había mantenido hacia él. [...]. Hacia 1935, al comprender que la dictadura fascista, lejos de acelerar el desarrollo hacia una revolución social, se iría contra la Unión Soviética en caso de una guerra, el Kremlin reversó el curso que llevaba y ordenó a sus secciones nacionales cooperar con todos 
los elementos de la población que no fueran hostiles a la URSS (pp. 1-2; traducción propia).

Lo que aquí nos indica Hook deja en claro al menos tres cosas fundamentales. En primer lugar, que lo único realmente importante para el régimen estalinista era la defensa de la Unión Soviética, lo que era muy acorde con su política del llamado "socialismo en un solo país" y que, por tanto, toda diferencia ideológica podría ser superada si los Estados y movimientos políticos renunciaban a su hostilidad frente al régimen de Stalin; en segundo término, que la nueva política oficial del comunismo internacional resultaba mucho más benévola que la anterior con los movimientos de carácter liberal, que tanta fuerza tenían en Estados Unidos y en otras partes del mundo; y que, por tanto, en tercer lugar, los movimientos políticos e intelectuales de carácter progresista verían a los comunistas no como sus más severos críticos, sino como nuevos aliados en la lucha contra la amenaza fascista proveniente de Italia y Alemania.

Esto no explica, desde luego, el hecho de que ese mismo Estado, el soviético, que buscaba emprender tareas comunes con las fuerzas liberales de Occidente, iniciara hacia adentro un proceso interno de purgas y persecuciones implacables contra los disidentes. Sí explica, sin embargo, que las denuncias que se hacían sobre las brutalidades del régimen soviético no tuvieran mayor resonancia en Occidente, no solo porque Moscú cuidaba mucho su relación con las fuerzas vivas de los países occidentales, sino porque esto ocurría muy lejos de América, poco le interesaba a los europeos (más preocupados por el avance de la barbarie nazi y fascista) y, sobre todo, porque lo que ocurría en la Rusia soviética solo era denunciado por un hombre que vivía casi preso en el exilio, Trotsky, que, además, se había declarado en abierta rebeldía, por razones aparentemente más personales que políticas, contra un sistema de gobierno que él mismo había ayudado a establecer -alguien que, por tanto, podía ser percibido simplemente como un traidor-.

La dimensión de lo que ocurría en Moscú por aquellos años, el modo como, mediante una estrategia rigurosamente planeada, los mismos hombres que hicieron la Revolución Bolchevique confesaron sin miramientos que se habían aliado, liderados por Trotsky (que ya vivía en el exilio desde hacía varios años), para derrocar el régimen comunista de la URSS y restaurar allí el capitalismo, las purgas y las ejecuciones extrajudiciales de intelectuales, militares y políticos de altísimo rango, y todo aquello que se dio en torno a estos procesos judiciales y 
políticos fue algo que solo se comprendió más tarde. Las denuncias de Trotsky, también el acusado por excelencia, fueron escasamente escuchadas, pues la gran mayoría seguía embelesada con la promesa de la realización final de la utopía comunista.

Para percibir la magnitud de los crímenes ligados a los procesos de Moscú, me permito citar solo un pequeño pasaje de la introducción que hizo Will Reissner (2008) en 1972 al informe de la Comisión Dewey conocido como Not Guilty:

Los procesos de Moscú, que estaban dirigidos contra los mejor conocidos y más influyentes oponentes políticos de Stalin, fueron solamente la punta de un iceberg mucho más grande: el de los arrestos, purgas, ejecuciones y otras formas de represión política que azotaron la Unión Soviética durante los años en que Stalin estuvo en el poder. Cuántos ciudadanos soviéticos fueron víctimas de esta época de terror es algo que nunca han revelado las autoridades soviéticas; sin embargo, una muestra de la dimensión de dichas purgas es algo que se puede ver en la información que trae a colación Khrushchev en el [...] Vigésimo Congreso y según la cual "de los 139 miembros y candidatos del Comité Central del partido que fueron elegidos en el decimoséptimo congreso [en enero de 1934], noventa y ocho personas -es decir, el 70\%- fueron arrestadas y ejecutadas (la mayoría de ellas ente 1937 y 1938)"; además, de los 1966 delegados a ese congreso, 1108 fueron arrestados por acusaciones de "crímenes antirrevolucionarios". Más del 80\% de estos delegados habían sido miembros por largo tiempo del Partido Comunista, pues se habían unido a él antes de la Revolución o durante la guerra civil (pp. 9-10; traducción propia).

Si los procesos de Moscú tuvieron muchos aspectos brutales -hombres hasta entonces admirados por su valentía, tesón e inteligencia confesaban haber participado de los crímenes más atroces y la gran mayoría de ellos eran de inmediato fusilados sin que hubiese lugar a que ejercieran su derecho a la defensa-, no menos brutal fue la persecución del Estado soviético contra un individuo en particular: León Trotsky ${ }^{6}$. Cuando comenzaron los procesos de Moscú, Trotsky

6 Cabe recordar que en dichos procesos, iniciados en 1936, el régimen estalinista hizo "confesar" una serie de delitos de todo tipo a casi todos los antiguos líderes de la Revolución y a los militares más 
vivía en Noruega en compañía de su segunda esposa, Natalia Sedova, pero no en condición de asilado o algo semejante, sino como un auténtico paria (se le había despojado de la ciudadanía soviética y ningún país lo quería aceptar en condición de refugiado, mucho menos otorgarle una nueva ciudadanía). Se mantenía en una condición de casi completa incomunicación, pues nadie parecía dispuesto a escuchar ni sus tesis filosóficas ni, mucho menos, sus críticas severas a la barbarie que por entonces empezaba a desatarse en la URSS.

A petición de Stalin -recuerda su nieto Esteban Volkov-, el gobierno noruego somete a Trotsky, en sus últimos seis meses de exilio, a un rígido arresto domiciliario, con el propósito de impedirle desmentir públicamente la avalancha de falsas acusaciones difundidas desde Moscú (Comisión Dewey, 2010, p. 12).

En esta circunstancia desesperada, la esperanza vendría para Trotsky desde el otro lado del océano, bajo la forma de dos acontecimientos distintos: en primer lugar, la constitución, en octubre de 1936, en los Estados Unidos, de un comité provisional para la defensa de León Trotsky, del que participaban tanto periodistas y dirigentes políticos como reconocidos intelectuales de carácter liberal, entre ellos el propio John Dewey. Dicho comité abogaba por el derecho de asilo para Trotsky y sugería la creación de una comisión internacional de investigación que examinara las acusaciones hechas contra él y que recaudara evidencias y testimonios para determinar su validez. En segundo término, la concesión del asilo, a comienzos de 1937, por parte del presidente de México, el general Lázaro Cárdenas, muy seguramente por mediación del conocido muralista Diego Rivera ${ }^{7}$. Trotsky llegó ese país latinoamericano en enero de ese mismo año, en compañía de Natalia, y fue alojado por varios meses en la casa de Rivera y Frida Kahlo.

destacados de la Guerra Civil posterior y, con base en tales "confesiones", claramente amañadas, los ejecutó de forma sumaria. Solo León Trotsky, que había sido expulsado del Partido y del país unos años antes y que, en condición de exiliado, había ido pasando de un país europeo a otro, escapó inicialmente a la venganza de Stalin.

7 Sobre las circunstancias y pormenores que rodearon el nacimiento de esta comisión de investigación, véase Hook, 1984, Roche, 1990/2010 y Farrell, 1950. 


\section{Origen y propósitos de la Comisión Dewey}

DESDE LA ÉPOCA EN QUE VIVÍA EN EL EXILIO en diferentes países europeos, Trotsky pidió ser procesado en un tribunal legalmente constituido. El régimen de Stalin, por supuesto, se negó a hacer tal cosa, pues le resultaba imposible garantizarle a su acusado un juicio público e imparcial. Una vez obtuvo el asilo en México, el propio Trotsky pidió la creación de una comisión internacional de investigación ante la cual pudiera ejercer su derecho a la defensa. Lo único que exigía era que esa comisión estuviese formada por personas de un carácter irreprochable y que se le permitiera ofrecer su versión de los hechos y aportar las pruebas documentales en su poder. En un discurso que fue transmitido telefónicamente desde Ciudad de México ante un grupo de personas reunido en el Hipódromo de Nueva York, el 9 de febrero de 1937, Trotsky hizo la siguiente promesa: "si esta Comisión decide que soy culpable en el más mínimo grado de los crímenes que me imputa Stalin, me comprometo de antemano a entregarme voluntariamente a las manos de los ejecutores de la GPU (la policía secreta soviética)" (Comisión Dewey, 2010, p. 31$)^{8}$.

Puesto que ya por entonces se había constituido en los Estados Unidos un comité para la defensa de León Trotsky, conformado por intelectuales y ciudadanos de las más altas calidades morales y sin compromisos políticos a favor o en contra de Trotsky, se formó a partir de este una Comisión Internacional de Investigación para examinar las acusaciones hechas contra Trotsky y su hijo en los procesos de Moscú y se nombró como presidente de dicha comisión al filósofo y educador norteamericano John Dewey. Durante ocho días y a lo largo de trece audiencias, entre el 10 y el 17 de abril de 1937, se le permitió a León Trotsky, en Coyoacán (Ciudad de México), presentar los argumentos para su defensa y desvirtuar una a una todas las acusaciones que contra él había levantado el régimen soviético?.

8 Un fragmento del video que registró la declaración de Trotsky está disponible en https://www. youtube.com/watch?v=J2g1yhntWgc.

9 Quien quiera seguir los pormenores de todas estas audiencias, tiene a su disposición la publicación del CEIP (Comisión Dewey, 2010). En este texto están registradas la totalidad de las audiencias de Coyoacán. Sobre el viaje a México y las personalidades de Dewey y Trotsky, véase Farrell, 1950. 
Antes de entrar en el contenido de las famosas audiencias de Coyoacán, es necesario aclarar su forma de operación. Para ello debemos distinguir entre tres entes distintos que a menudo se confunden, aunque estén muy relacionados: (1) el Comité Norteamericano para la Defensa de León Trotsky, constituido en los Estados Unidos en octubre de 1936 por un amplio número de intelectuales, políticos y periodistas ${ }^{10}$; (2) la Comisión Internacional de Investigación sobre los Procesos de Moscú, que se formó después de los dos primeros procesos por la presión ejercida por los comités de defensa de Trotsky ${ }^{11}$; y (3) la Subcomisión Dewey o Subcomisión de Coyoacán, presidida por John Dewey, que escuchó a Trotsky en México en abril de $1937^{12}$. Para los propósitos del presente trabajo, cuando hablemos de la Comisión Dewey, nos referiremos a la Comisión Internacional de Investigación sobre los Procesos de Moscú. Para referirnos a lo que

10 Aunque en este comité participaron muchas personas distintas (llegó a tener alrededor de cuarenta miembros), las más destacadas entre ellas fueron filósofos como John Dewey, Sidney Hook, Horace Kallen y Max Eastman, periodistas como Herbert Solow, Suzanne La Follette y Benjamin Stolberg y dirigentes del Partido Socialista Norteamericano como Norman Thomas y Devere Allen. Este comité, como ya se indicó, tenía dos objetivos básicos: la obtención del derecho de asilo para Trotsky y la formación de la Comisión Internacional de Investigación sobre los Procesos de Moscú, que debería examinar todas las evidencias y testimonios recaudados (sobre todo los del propio Trotsky y su hijo León Sedov) y presentar un informe público con sus conclusiones.

11 Esta comisión internacional se organizó en marzo de 1937 con sede en Nueva York y se subdividió a su vez en tres subcomisiones que realizaron sus labores en los meses siguientes: la que, presidida por Dewey, escuchó a Trotsky en Coyoacán, entre el 10 y el 17 de abril, sin duda la más importante; una subcomisión francesa, presidida por Modigliani, que sesionó en París, y que escuchó al hijo de Trotsky, entre el 11 de mayo y el 22 de junio; y una subcomisión de Nueva York, que se reunió en el mes de julio para escuchar a algunos testigos norteamericanos.

12 Esta subcomisión, que fue la que se reunió en la Casa Azul de Diego Rivera y Frida Kahlo, en Coyoacán, Ciudad de México, estaba conformada por cinco personas: John Dewey, en calidad de presidente de la subcomisión; Suzanne La Follette, escritora y exeditora de New Freeman, en calidad de secretaria; Otto Ruehle, un antiguo miembro del Parlamento alemán y biógrafo de Karl Marx, que residía por entonces en Ciudad de México; Benjamin Stolberg, escritor y periodista norteamericano; y Carleton Beals, un escritor y profesor universitario de California que, por desavenencias con otros miembros de la subcomisión, renunció a ella después de la decimoprimera sesión. Aparte de las cinco personas ya mencionadas, asistieron a las audiencias de Coyoacán dos abogados (John Finerty, como asesor legal de la subcomisión, y Albert Goldman, en calidad de abogado de Trotsky); León Trotsky y su secretario Jan Frankel, en calidad de testigos; Albert Glotzer, como taquígrafo; y un cierto número de representantes de la prensa e invitados, para un total de aproximadamente cuarenta personas. 
ocurrió en Coyoacán, hablaremos, según sea el caso, de la subcomisión o las audiencias de Coyoacán.

¿De qué se acusaba a León Trotsky y a su hijo, entonces, y por qué cargos fueron condenados? John Dewey, en su discurso inaugural de las audiencias ("Introductory Statement of the Commission of Inquiry”) en Coyoacán, resume las acusaciones lanzadas contra ellos (dieciocho cargos en total), en los siguientes términos:

[...] León Trotsky ha sido acusado de una serie de crímenes contrarrevolucionarios cometidos a lo largo de un cierto número de años. Ha sido acusado de instigar actos de terrorismo individual que tenían por propósito el asesinato de líderes del Partido Comunista y del gobierno de la Unión Soviética; de organizar y dirigir numerosos intentos de sabotaje industrial y de "maniobras de distracción”; de destrozos en fábricas y trenes que han tenido por resultado grandes pérdidas de vidas; de iniciar y promover el espionaje en la URSS por parte de agentes de naciones imperialistas; de participar en conspiraciones con la Gestapo en Alemania y, a través de sus agentes, con oficiales de la inteligencia japonesa; de conspirar, junto con representantes oficiales de la Alemania nazi y del Japón, para ayudar a esas naciones, de cualquier forma que fuese posible, a provocar y ganar una guerra en que ellas debían involucrarse contra la URSS, y ello con medidas entre las que estarían incluidas la obstaculización de la movilidad y de la provisión de los suministros militares necesarios, el derribo de trenes, etc. Finalmente, ha sido acusado de hacer un acuerdo con Alemania y Japón para cederles territorios de la URSS a esos países después de que estos obtuvieran la victoria en la guerra que proyectaban; de pactar un acuerdo comercial por medio del cual se otorgarían especiales privilegios comerciales a Alemania, además de hacerle concesiones mineras, comerciales, etc. Se ha argumentado en su contra diciendo que el objetivo de estos actos criminales de carácter contrarrevolucionario habría sido el de restaurar el capitalismo en la URSS y el de transferir el poder político en dicho país a los líderes de las facciones opositoras, entre los que se incluye al propio Trotsky (Dewey, Later Works 11, pp. 307-308; traducción propia).

¿En qué consistieron propiamente estas audiencias de Coyoacán, qué pretendían y hasta qué punto lo consiguieron? La mejor respuesta a estas preguntas nos la ofrece el informe que esta subcomisión presentó unos meses 
después a la Comisión Internacional de Investigación sobre los Procesos de Moscú en un texto que inicialmente fue publicado como un panfleto de quince páginas bajo el título La verdad está en marcha (Truth Is on the March), en recuerdo de la consigna con la que Emile Zolá concluyó el famoso affaire Dreyfus. En este documento, firmado por Dewey y otros comisionados, quedan establecidos algunos elementos básicos para la comprensión de las características de la Comisión Dewey; entre ellas cabe destacar las siguientes:

1. La función que cumplió la subcomisión presidida por Dewey en México no fue ni de juez ni de fiscal. Por lo tanto, no le correspondía ni acusar a Trotsky ni defenderlo; y tampoco le correspondía pronunciar una sentencia absolutoria o condenatoria. Su función era puramente investigativa, como lo deja claro su presidente y queda consignado en el texto "Truth Is on the March":

[...] estuvimos en México solamente como un cuerpo de investigación y en orden a recoger el testimonio del señor Trotsky con respecto a las acusaciones hechas contra él en las confesiones de los acusados de Moscú, a aceptar los documentos que él quisiera presentar en su defensa y a reportar a la Comisión en pleno, sobre la base de la evidencia recaudada, cuál debía ser la decisión con respecto a si el caso del señor Trotsky ameritaba o no una investigación ulterior (Dewey, $L W 11$, p. 310; traducción propia).

2. Trotsky no compareció ante la subcomisión en calidad ni de procesado ni de acusado, sino de testigo. La razón era clara: si bien había sido condenado, aunque no procesado, en los juicios de Moscú, en los que nunca fue escuchado ni tuvo ocasión alguna para la defensa, haberlo obligado a comparecer como procesado o acusado hubiera equivalido a reconocer la validez de tales acusaciones, que era precisamente lo que estaba en discusión. No solo se trataba de que Trotsky no se considerara ni acusado ni procesado (de hecho, fue él mismo el que solicitó ser escuchado por una comisión internacional de investigación), sino que era imposible considerarlo así, pues en los procesos de Moscú nunca había sido procesado; solo había sido condenado. La Subcomisión Dewey no acusaba a Trotsky de nada y, por tanto, tampoco tenía que abrir un proceso para examinar acusaciones que no había formulado. No era un tribunal, sino una comisión de investigación que no buscaba otra cosa que determinar si eran o no legítimas las acusaciones hechas contra Trotsky y los procedimientos utilizados 
para juzgarlo en ausencia. Trotsky y su secretario comparecían, entonces, como testigos que darían a la subcomisión su testimonio y su versión de los hechos y le proporcionarían todas las evidencias documentales que les fuera posible recopilar. Con respecto a su actitud como testigo, Dewey señala lo siguiente:

A lo largo de las audiencias, [Trotsky] pareció siempre dispuesto a cooperar con la Comisión en sus esfuerzos por establecer la verdad en todos los aspectos de su vida y de su actividad política y literaria. Contestó prontamente, y con toda amabilidad y sinceridad, a todas las preguntas que le hicieron tanto el abogado como los miembros de la subcomisión (Dewey, $L W 11$, p. 313; traducción propia).

3. El punto de partida de la comisión de investigación no podía ser otro que los propios procesos de Moscú y las acusaciones allí presentadas por el fiscal Vyshinsky. De dichos procesos había un reporte por escrito, traducido al inglés, con el que pudieron contar los comisionados ${ }^{13}$. Puesto que, según el fiscal ruso, había dos testimonios principales en los que se basaron los procesos (por un lado, los que se refieren a la "conexión histórica" de los trotskistas con actividades criminales; por el otro, las confesiones de los acusados), dichos testimonios debían ser evaluados. Y, puesto que el propósito de la subcomisión era determinar la legitimidad de dichos procesos, debía examinar las acusaciones lanzadas contra Trotsky a la luz de su vida y obra (que en algunos casos había sido alterada por el fiscal Vyshinsky). El trabajo de la comisión Dewey era, entonces, en cierto modo el de investigar si había sido correctamente conducido el proceso de investigación desarrollado en Moscú en los juicios de agosto de 1936 y enero de $1937^{14}$.

4. En el trabajo de la subcomisión, por no tratarse propiamente de un tribunal, sino de algo más parecido a una comisión de la verdad, las pruebas que se presentaron no podían ser del tipo de las que se presentan ante un órgano

13 Dewey estudió muy concienzudamente dichos reportes, lo mismo que las obras de Trotsky (véase Farrell, 1950).

14 Hay que recordar que solo estos dos primeros procesos fueron conocidos por la Comisión Dewey, pues los otros dos procesos se realizaron con posterioridad a las audiencias de Coyoacán y al trabajo de dicha comisión. 
judicial. Se trataba en lo esencial, además del testimonio de Trotsky y de uno de sus secretarios, John Frankel, de pruebas documentales como las siguientes: declaraciones juramentadas de testigos relativas a las actividades de Trotsky en sus años de exilio, cartas de Trotsky y dirigidas a él, una fotocopia del pasaporte de su hijo, telegramas, declaraciones de empleados públicos sobre ciertos acontecimientos, citas de los escritos de Trotsky y otros autores, etc. Muchos de estos documentos buscaban desvirtuar los testimonios de los acusados en los procesos de Moscú que señalaban a Trotsky de haberse reunido con ellos para tramar una conspiración terrorista contra la URSS. Aparte de todo lo anterior, Trotsky puso a disposición de la comisión sus archivos en México y les reveló dónde se encontraban sus archivos europeos.

El trabajo de la Comisión Dewey ${ }^{15}$ no se desarrolló sin una serie de tropiezos de todo tipo que empezaron desde el momento mismo de su constitución. La sola idea de que se conformara en los Estados Unidos un comité para la defensa de León Trotsky fue vista por muchos miembros de la comunidad intelectual norteamericana como una toma de posición a favor de uno de los bandos en pugna

15 De las audiencias de Coyoacán, y en general de la investigación de la Comisión Dewey sobre las acusaciones hechas contra Trotsky, tenemos a disposición al menos cuatro tipos de documentos fundamentales: 1) El caso León Trotsky, el libro que contiene el registro completo de las audiencias que tuvieron lugar en Coyoacán en abril de 1937 y en las que la comisión presidida por Dewey recogió el testimonio de Trotsky y uno de sus secretarios; fue publicado en español en el año 2010 (véase Comisión Dewey, 2010). 2) Not Guilty: así se conoce el informe completo en que la Comisión Dewey presenta los resultados y conclusiones de las diversas investigaciones, realizadas a lo largo del año 1937, por sus diversas subcomisiones en México, París y Nueva York; es un informe de más de 500 páginas en que se desmenuza parte por parte todo el proceso que llevó a declarar inocentes a Trotsky y a su hijo por parte de la comisión y se confrontan los testimonios y documentos ofrecidos por Trotsky, Sedov y otros testigos con las acusaciones y testimonios de los procesos de Moscú. Este texto no ha sido traducido al español hasta el momento (véase Dewey Commission, 2008). 3) "Los escritos y conferencias de Dewey sobre el caso Trotsky": se trata de una serie de textos escritos por John Dewey (que están reunidos en sus Later Works bajo el título “The Leon Trotsky Inquiry”, véase Dewey, $L W 11$, pp. 303-336), y en los cuales Dewey hace diversos pronunciamientos públicos sobre el juicio a Trotsky, su relevancia histórica y la importancia que tiene el establecimiento de la verdad para la vida democrática. 4) Escritos de otros autores sobre el caso Trotsky y la participación de Dewey en él, libros y artículos en los que tanto estudiosos de la obra filosófica de Dewey como partidarios de Trotsky examinan lo ocurrido en este acontecimiento de relevancia histórica. En este grupo de documentos se destacan "Dewey in Mexico" de James Farrell (1950) y "Memories of the Moscow Trials", de Sidney Hook (1984). (En la actualidad, preparo una compilación de muchos de estos textos traducidos). 
en la Unión Soviética y, puesto que muchos de ellos tenían un compromiso partidista con la perspectiva estalinista, vieron en este comité de defensa, y luego en la Comisión Dewey, un blanco para sus críticas. No faltaron tampoco quienes acusaron, al mejor estilo de los partidarios de Stalin, de "trotskistas" a muchos de sus miembros. Y fueron muchos también los que pasaron de las denuncias a las amenazas. Ello llevó a que dos de las principales figuras de este comité, el propio Dewey y el también filósofo Horace Kallen, publicaran en la página 4 del New York Times del 17 de febrero de 1937 una declaración pública, titulada "Statement by the American Committee for the Defense of Leon Trotsky", sobre las razones que los llevaron a participar en este caso. Cito, de dicha declaración, su pasaje más representativo:

No estamos comprometidos en forma alguna, y no tienen relación con este asunto, los puntos de vista políticos de León Trotsky. Tampoco estamos interesados en prejuzgar con respecto a la cuestión de la verdad o falsedad de las acusaciones hechas contra él. Nuestro único interés es el de asegurarle a él el ejercicio pleno de sus derechos como ser humano ante el tribunal de la opinión pública y bajo la ley de una tierra en la cual, y de acuerdo con la tradición liberal más clásica, se le deben reconocer los mismos derechos a todas las personas que se encuentren en circunstancias similares. Si fuera Stalin el que estuviera en la misma posición precaria, igualmente estaríamos defendiendo de forma vehemente su derecho a ser escuchado antes de ser declarado culpable o inocente. Las cuestiones fundamentales que están implicadas aquí son mucho más importantes que lo que concierne específicamente al señor Trotsky, pues, si a él le fuese negado el derecho que tiene de presentar su caso ante el mundo, los derechos de todos los demás estarían en peligro. En el pasado, muchos de nosotros, los norteamericanos, hemos invertido una considerable cantidad de tiempo, energía y recursos en defender los derechos de los comunistas, independientemente de que ellos fuesen culpables o inocentes, en orden a que ellos puedan recibir justicia ante la ley. Ellos deberían ser, entonces, los últimos en negar a otros los derechos que han exigido para sí mismos. Y, ciertamente, ningún liberal honesto podría fallar a la hora de estar de nuestro lado (Dewey, $L W 11$, p. 598; traducción propia). 
Si los comunistas ortodoxos hacían todo lo que estaba a su alcance para evitar que se conformara la comisión, los pensadores liberales más reconocidos mostraban poco entusiasmo con el asunto y preferían quedarse al margen. Este fue el caso de personajes tan reconocidos como Albert Einstein, Bertrand Russell y George Santayana (Hook, 1984). La verdad es que al principio el propio Dewey no parecía interesado en participar en la comisión, y menos aún en presidirla. Era comprensible: recibía muchas presiones de diversos lados, que lo afectaban a él y a su familia, tenía que dedicar tiempo a otros proyectos muy importantes (como la redacción de su gran obra sobre la lógica como una teoría de la investigación) y, sobre todo, estaba cerca de cumplir los setenta y ocho años. Todo indica que Dewey solo se decidió a presidir la comisión que viajaría a México a tomar el testimonio de Trotsky cuando descubrió que el propio Kremlin había intervenido para que sus amigos sindicalistas lo disuadieran de viajar. Sorprendente fue en todo caso la actitud de algunos sectores de la opinión pública norteamericana de tradición liberal; así, por ejemplo, New Republic, una de las revistas más reconocidas e independientes de los Estados Unidos, en la que Dewey había escrito muchas veces y de la que había sido fundador y editor, cuestionó una y otra vez los propósitos de la Comisión de Investigación, hasta tal punto que Dewey se vio obligado a renunciar a su participación en el comité editorial de la revista ${ }^{16}$.

No menos complicada para la subcomisión que viajó a México fue la actitud de uno de sus miembros: el comisionado Carleton Beals, un periodista y profesor norteamericano especializado en temas latinoamericanos que, desde las primeras audiencias, asumió una actitud hostil, primero hacia Trotsky y luego hacia algunos miembros de la subcomisión, entre ellos el propio John Dewey. Aunque no esté claro si su actitud se debía a compromisos con sectores políticos interesados en que fracasara el trabajo de la Comisión Dewey o simplemente a conflictos de orden personal, lo cierto es que en más de una ocasión sus intervenciones fueron una fuente de tensión en las audiencias. Finalmente, en la audiencia de la tarde del 16 de abril, el comisionado Beals le planteó a Trotsky una pregunta que muchos juzgaron malintencionada, pues se basaba

16 Sobre este y muchos otros asuntos ligados a los procesos de Moscú y a la constitución de la Comisión Dewey, son muy ilustrativos los "Recuerdos de los procesos de Moscú", de Sidney Hook (1984), en los que me he apoyado en esta parte. 
en informaciones que no habían sido verificadas, ante lo cual el asesor legal de la comisión, John Finerty, objetó la pregunta y su sentido. El comisionado Beals exigió la renuncia del asesor legal, lo que no fue aceptado por la comisión. Beals, entonces, renunció y empezó a dar declaraciones a la prensa en contra de la comisión y de sus miembros. El asunto fue tan incómodo para Dewey y los demás miembros de la subcomisión que este le dedicó una parte de su informe básico a clarificar los hechos y a mostrar por qué la actitud del señor Beals no era la adecuada. Concluye así Dewey este enojoso asunto:

Aunque lamentamos profundamente la renuncia del señor Beals, no nos perturba. La Comisión está investigando una gran controversia histórica. Poderosos intereses están aquí involucrados intentando perturbar y sabotear nuestro trabajo. Por tanto, podemos esperar que nuevos intentos de este tipo se presenten en el futuro (Dewey, $L W 11$, p. 314; traducción propia).

Y Dewey tendría razón: las presiones seguirían incluso tiempo después de que terminaran las audiencias de Coyoacán ${ }^{17}$, después de que se publicara el informe de la comisión e incluso varios años más tarde, cuando surgiera la controversia en torno al libro de Joseph Davies (1941) sobre los procesos de Moscú y a la película que se hiciera sobre dicha obra. Pero de ello nos ocuparemos más adelante.

El trabajo de la Comisión Dewey se extendió a lo largo de todo el año de 1937. Después de las audiencias de Coyoacán, otros miembros de la comisión recogieron el testimonio de León Sedov en París y de otros testigos en la ciudad de Nueva York. Con todos los elementos recogidos, y después de un cuidadoso estudio donde confrontaron fuentes y certificaron la validez de los documentos ofrecidos, la Comisión Internacional de Investigación, con Dewey como su cabeza visible, pronunció su veredicto hacia el final de ese mismo año: 1) los procesos de Moscú habían sido burdos montajes (frame-ups); y 2) Trotsky y su hijo eran inocentes. Pero, ¿qué les permitió llegar a conclusiones tan contundentes?

17 En enero de 1938, recién presentado el informe de la Comisión Dewey, había periodistas que afirmaban que esta no había servido de nada, pues no había logrado probar nada. A uno de ellos, Seldon Rodman, le responde Dewey en su texto de enero de 1938 titulado "En defensa de las audiencias mexicanas". Véase "In Defense of the Mexican Hearings", en: Dewey, $L W 11$, pp. 347-348. 
Not Guilty ("No culpable" o, si se prefiere, "Inocente") es el título con que se conoce el informe en donde se presentan el análisis y las conclusiones de la comisión formada en 1937, y presidida por John Dewey, para investigar las acusaciones hechas contra León Trotsky y su hijo León Sedov en los procesos de Moscú. Entiendo que se haya elegido dicho título, si lo que se pretendía era causar un impacto en la opinión pública ante un caso tan notable; sin embargo, creo que resulta inadecuado al menos por dos razones. La primera es que contradice lo que la propia comisión se había planteado como su fin: el de actuar como un cuerpo investigativo más que judicial, es decir, que su preocupación no era tanto determinar si Trotsky y su hijo eran culpables o inocentes, sino el de establecer si los procesos de Moscú habían sido adecuadamente conducidos y si, con base en la evidencia recaudada, el caso de Trotsky y su hijo ameritaba o no una investigación ulterior ("Truth Is on the March", en: Dewey, $L W 11$, p. 310). La segunda razón es que puso el énfasis sobre la segunda conclusión (que Trotsky y Sedov eran inocentes), que no era la fundamental, pues solo era una consecuencia de la conclusión verdaderamente importante: que los procesos de Moscú fueron burdos montajes judiciales.

La inocencia era en este caso una conclusión simplemente necesaria, pues no fue posible comprobar, a pesar de todos los esfuerzos que hizo la comisión, ninguno de los delitos de los que se les acusaba. En cambio, se descubrieron mentiras evidentes, pues muchas de las cosas que confesaron los acusados y testigos de los procesos de Moscú se revelaron como absolutamente falsas e incluso como totalmente imposibles. Lo verdaderamente importante no era, entonces, si Trotsky y Sedov debían ser declarados inocentes o culpables: claramente eran inocentes, o al menos no culpables, en el sentido de que ninguno de los crímenes que se les imputaron pudo ser comprobado. Lo verdaderamente importante es otra cosa: ¿de qué procedimientos se valió el sistema judicial soviético para establecer su culpabilidad? Aquí es donde el informe de la Comisión Dewey resulta realmente revelador. Antes de entrar a ocuparnos de su contenido, recordemos brevemente cómo se construyó este informe.

El trabajo de la Comisión Internacional de Investigación consistía en determinar si los veredictos de culpabilidad proferidos contra Trotsky y Sedov en los procesos de Moscú se basaban en hechos comprobados (o al menos comprobables) 
y, por supuesto, si tales veredictos resultaban o no creíbles y legítimos. Esto debían determinarlo acudiendo a muchas estrategias y fuentes distintas: el examen de las transcripciones (al inglés) de los expedientes de los procesos de Moscú, los testimonios directos de Trotsky, Sedov y todos los demás testigos que pudiesen aportar algún elemento que obrase a favor o en contra de ellos y, también, todo un acervo documental que incluía desde cartas personales hasta pasajes de las obras escritas por Trotsky y otros líderes revolucionarios. Se esperaba también que las autoridades soviéticas pudieran proporcionar a la comisión todas aquellas pruebas, materiales o documentales, que sirvieran para un mejor examen de la cuestión, pero la comisión, a pesar de que lo intentó de diversos modos, nunca recibió la ayuda de las autoridades soviéticas. De ello deja constancia el informe de la Comisión Dewey (Dewey Commission, 2008, p. 32).

Después de las tres audiencias ya señaladas (las de Coyoacán, presididas por el propio Dewey, y las de unas subcomisiones de carácter rogatorio instaladas en París y Nueva York en los meses sucesivos), y tras un estudio detallado de la documentación aportada por Trotsky y Sedov, la comisión en pleno redactó y firmó las conclusiones básicas de su investigación el 21 de septiembre de 1937 y nombró un comité editorial (formado por John Dewey, Suzanne La Follette y Benjamin Stolberg) al que encargó la redacción del informe de acuerdo con las conclusiones ya establecidas. Como el propio Dewey reconoce, la escritura efectiva del informe estuvo a cargo de Suzanne La Follette, pues fue ella la que revisó cuidadosamente todos los documentos que les fueron aportados, sopesó las evidencias y le dio al informe la forma que finalmente tuvo. El informe final fue aprobado por los diez miembros de la comisión, presentado ante la opinión pública en diciembre de 1937 y publicado en 1938.

¿Qué aportó el informe de la comisión para establecer la inocencia de Trotsky y Sedov y, sobre todo, en qué se apoyó para determinar que los procesos de Moscú fueron montajes judiciales? Antes de entrar en los detalles propiamente jurídicos, tal vez sea conveniente considerar al menos cinco aspectos en que los procesos de Moscú rayaron en el absurdo:

1. Todos los acusados eran viejos bolcheviques que habían actuado al lado de Lenin y que eran considerados auténticos héroes de la Revolución de Octubre: ¿cómo se explica que, de un día para otro, todos ellos se hubieran puesto de acuerdo, liderados por un hombre que vivía en el exilio (Trotsky), para atacar al 
Estado soviético y para intentar asesinar a sus principales líderes, incluyendo al propio Stalin?

2. Las acusaciones eran gravísimas, pero bastante inverosímiles: se les acusaba, entre otras muchas cosas, de actos terroristas de diversa índole (atentados, sabotajes, etc.) e incluso de aliarse con poderes extranjeros, como la Alemania de Hitler, para destruir la Unión Soviética y restaurar el capitalismo en Rusia. ¿Era coherente que un hombre que vivía prácticamente confinado en el exilio como Trotsky, que siempre había criticado los métodos terroristas y que era un enemigo declarado del nazismo, pudiera planear tales acciones, coordinarlas de forma perfecta desde el extranjero y utilizar a los demás acusados de los procesos de Moscú como títeres a su servicio?

3. La conducta de los acusados en el banquillo era muy sospechosa; su autoincriminación, el hecho de que hombres entregados por años a la lucha revolucionaria confesaran como mansos corderos toda una serie de crímenes espantosos en contra de su país, aun a sabiendas de que ello les costaría en muchos casos su propia vida. ¿Cómo podía explicarse un hecho tan fuera de razón? ¿Qué razones tenían estos hombres para hacer ese tipo de confesiones? ¿Mediante qué métodos se podían conseguir tales cosas?

4. El hecho de que, cuando se examinaron los procesos de Moscú por parte de los miembros de la comisión, lo más notorio fue la ausencia de evidencia material significativa. El fiscal de estos procesos, por ejemplo, pidió la condena para algunos a partir de supuestas cartas escritas por Trotsky en donde había instrucciones terroristas; sin embargo, tales cartas nunca se presentaron como evidencias. Peor aún: muchos hechos que se mostraron como ciertos y definitivos, una vez se indagó a fondo sobre ellos, no solo resultaron muy inciertos, sino en muchos casos improbables, cuando no absolutamente imposibles. Volveremos sobre este punto.

5. Más sorprendente que todo lo anterior fue la actitud de muchos gobiernos extranjeros y de muchos intelectuales que se decían "liberales" en Europa, los Estados Unidos y otras partes, que prefirieron dejar de lado el asunto, simplemente ocultándolo, o -lo que es peor aún- hicieron todo lo posible para justificar las prácticas corruptas que se pusieron en juego en los procesos de Moscú.

El informe de la Comisión Dewey, si bien aporta muchos elementos para comprender lo mucho de absurdo que hubo en los procesos de Moscú, tiene la estructura de un informe investigativo que no se centra en los casos particulares 
(aunque buena parte de él está dedicado a examinar una serie de testimonios de los acusados ${ }^{18}$ ), sino en intentar develar la estrategia seguida por quienes conducían dichos procesos, y en particular el fiscal Andrei Vyshinsky. La afirmación de que los procesos de Moscú fueron simples montajes judiciales se basa, para Dewey y los demás miembros de la comisión, en por lo menos las siguientes razones:

1. No se hizo esfuerzo alguno por establecer la verdad de los hechos criminales que se les imputaban a los acusados. Esta es la primera conclusión de la Comisión Dewey. La conducción de los procesos no fue la adecuada, pues no fue guiada por el único principio que vale en estos casos: el de seguir un procedimiento que garantice el establecimiento de la verdad hasta donde ello es posible dentro de las limitaciones humanas y con los recursos y métodos disponibles en el momento. Puesto que el fin no era establecer la verdad, sino crear una situación política determinada, la del castigo de todos aquellos que pudieran oponerse al régimen de turno, lo importante era demostrar la culpabilidad de los acusados y no establecer la verdad de los hechos. Establecido esto, los métodos empleados podían ser de cualquier tipo, siempre y cuando se acomodaran al fin establecido. De esta forma, la delación, la confesión forzada y la ejecución extrajudicial resultaban mecanismos legítimos, puesto que el fin era demostrar la culpabilidad de los acusados.

Que los procesos de Moscú eran perfectamente consistentes con el procedimiento legal soviético fue uno de los argumentos que con mayor frecuencia invocaron sus defensores. La Comisión Dewey no solo mostraría que tal cosa no era cierta, como veremos a continuación, sino que argumentó sobre bases éticas que ese criterio, de haberse cumplido, no hubiera sido una justificación suficiente. Dice al respecto el informe de la Comisión Dewey:

18 El informe de la Comisión Dewey tiene cinco partes y tres apéndices. Las dos primeras son introductorias, pues se ocupan de la comisión misma y de las bases de su investigación. La tercera, la más larga y la más importante en mi concepto, se ocupa de los cargos levantados contra los acusados, del procedimiento de los tribunales soviéticos y del examen detallado de los testimonios de cada uno de los principales acusados en los procesos de Moscú. Las partes cuarta y quinta examinan qué tan creíbles resultan los cargos levantados contra los acusados, el valor que pueden tener las confesiones realizadas por ellos y la llamada "conexión histórica” aducida por el fiscal del caso como argumento para determinar la culpabilidad de los acusados. 
En opinión de la comisión, la adhesión a un procedimiento legal dado no es el criterio básico para juzgar un proceso. El criterio básico debe ser la justicia y honestidad en el intento por establecer la verdad. Es bastante posible, como lo ha probado la historia, que ciertas personas hayan sido falsamente condenadas sin haberse apartado para nada de la ley que rige los procesos criminales. Esta cuestión solo puede ser planteada a la luz de lo que debería ser la teoría del procedimiento criminal en un sistema cualquiera de jurisprudencia, a saber: que su propósito es hacer posible el establecimiento de la verdad que es posible alcanzar en un caso dado. Únicamente en la medida en que un procedimiento cualquiera cumpla con este propósito resulta justificable; y solamente en la medida en que el fiscal y la corte se conformen tanto al espíritu como a la letra de un proceder justificable podrán sostener que salvaguardan el derecho de las personas acusadas a ser condenadas o absueltas sobre la base de la verdad de los cargos levantados contra ellas (Dewey Commission, 2008, pp. 46-47; traducción propia).

2. El Fiscal del caso, el señor Vyshinsky, trastocó muchos de los hechos y, en particular, falsificó a su amaño el papel jugado por Trotsky antes, en y después de la Revolución de Octubre. Desde las primeras sesiones de las audiencias de Coyoacán, este fue uno de los puntos que Dewey, como presidente de la comisión, se propuso clarificar, pues todo indicaba que algunos aspectos de la vida y obra de Trotsky (por ejemplo, la relación que mantuvo con Lenin) fueron claramente alterados para los fines del juicio que se le adelantaba en su ausencia. En un largo discurso de defensa pronunciado durante la última de las sesiones, en la tarde del 17 de abril de 1937, Trotsky se dedicó precisamente a aclarar algunos aspectos de su biografía que fueron, según él, deformados por Vyshinsky (Comisión Dewey, 2010, pp. 491-498).

3. La forma de proceder de Vyshinsky violaba de forma flagrante las reglas del procedimiento legal existentes en Rusia. El capítulo 7, uno de los más interesantes del informe de la Comisión Dewey, está dedicado al examen del procedimiento de la Corte soviética. Allí no solo se establece el principio de que no es la adhesión a un procedimiento legal determinado -en este caso el existente en su momento en la URSS- lo que se constituye en justificación válida para el proceder de los tribunales, sino que se muestra de forma muy clara que el procedimiento seguido en los procesos de Moscú violó de forma flagrante 
la ley soviética sobre el procedimiento en asuntos criminales en por lo menos los siguientes aspectos: a) los acusados fueron condenados sobre la base de sus propias confesiones y, en el caso de los testigos que se autoinculparon, sus confesiones no fueron corroboradas por medio de ninguna evidencia documental importante; b) los testigos que fueron convocados para testificar en contra de los acusados terminaron inculpados ellos mismos a raíz de sus testimonios; c) Trotsky y su hijo fueron condenados exclusivamente con base en los testimonios de testigos (que a la vez eran acusados), lo que, según el propio derecho soviético constituye la evidencia "menos meritoria"; d) el Fiscal Vyshinsky no siguió las reglas establecidas en el derecho soviético al presentar ciertas pruebas materiales (como el pasaporte de uno de los acusados, una supuesta carta abierta de Trotsky que nunca muestra, algunos cuadernos de los acusados, fotografías, etc.), con lo cual resultaba sospechosa la forma como se recaudó la evidencia, pero sobre todo que el material probatorio recaudado no resultaba relevante para establecer ni la existencia de una supuesta conspiración trotskista ni la conexión de los acusados con dicha "conspiración". Sin duda hay, además de esto, otra serie de errores procedimentales por parte del fiscal en asuntos como la forma de citar a los testigos o de confrontar sus testimonios, pero sobre todo en el hecho fundamental de que no se hizo ningún esfuerzo por hacer comparecer, y darles ocasión para que presentaran su versión de los acontecimientos, a los principales acusados: Trotsky y Sedov ${ }^{19}$.

4. Las confesiones de los acusados en los procesos de Moscú no podían tener un valor probatorio absoluto. Este fue un punto central en el análisis de la Comisión Dewey: si la condena que se profirió contra Trotsky y los demás acusados se basó sobre todo en confesiones de los propios acusados, es porque se concedió a tales testimonios un valor probatorio prácticamente absoluto. Cualquiera podría decir que los testimonios eran tan elocuentes que con ello resultaba

19 Toda esta parte procedimental está cuidadosamente analizada en el ya citado capítulo 7 del informe de la comisión. Véase Dewey Commission, 2008, pp. 46-62. Cabe destacar que la comisión hizo todo su análisis partiendo de lo establecido en un conocido texto del derecho criminal soviético, Procesos criminales. Un texto para las escuelas de leyes y para cursos jurídicos, del profesor M. S. Strogovich, publicado en Moscú en 1936 y conocido por el Fiscal Vyshinsky, pues fue su editor. Esto deja en claro que Vyshinsky violó abiertamente reglas que de ningún modo podían resultarle ajenas. 
suficiente. Sin embargo, en un proceso judicial esto resulta del todo inadmisible, por muy diversas razones: porque los testigos pueden ser falsos, porque pudieron ser forzados a hacer determinadas confesiones (tanto para evitar un mal mayor para ellos o sus seres más cercanos, como para buscar algún tipo de beneficio), porque utilizan su testimonio como un modo de inculpar a otros, de salvarse ellos o simplemente de ejercer venganza; y por muchos motivos más. Los testimonios tienen que ser examinados, confrontados ante el testigo mismo y contrastados con las versiones de otros testigos, tienen que ser evaluados a la luz de anteriores y nuevas evidencias, etc. Pero nada de eso se hizo en los procesos de Moscú: simplemente se condenó y ajustició a hombres cuya culpabilidad nunca se demostró claramente y se les ejecutó sin posibilidad alguna de apelación. Y ello vale también para aquellos casos en que los propios acusados se condenan a raíz de sus propias confesiones. ¿Por qué una confesión de culpa ha de tener un valor absoluto? ¿Acaso no se autoengañan las personas? ¿Acaso algunos, en un gesto que puede ser tan altruista como culpable, prefieren condenarse a sí mismos con el fin de proteger a otros?

5. Sobre todo, muchas de las acusaciones lanzadas contra Trotsky se desvirtuaron por completo ante el descubrimiento de que muchos de los hechos señalados por los acusados de los procesos de Moscú eran simples invenciones (por ejemplo, se pudo establecer que las tres entrevistas que dijeron algunos de los acusados haber sostenido con Trotsky en Copenhague, París y Oslo nunca tuvieron lugar) o evidentes falsedades. Cito solo tres de los ejemplos más notorios: a) uno de los acusados (Pyatakov) dijo haber recibido instrucciones de Trotsky para perpetrar actos terroristas y que, para ello, viajó a Oslo en diciembre de 1935; pero hay evidencias irrefutables de que en el aeropuerto de Oslo no aterrizó un solo avión en ese terrible invierno. b) Uno de los testigos de los procesos de Moscú (Holtzman) dijo haberse reunido con León Sedov en el Hotel Bristol en Copenhague; sin embargo, es claro - por los registros de su pasaporte y por otras evidencias recogidas- que no solo Sedov no estaba por aquella época en Dinamarca (había evidencias y testimonios dignos de crédito de que se encontraba por entonces en Berlín), sino que no había movimientos trotskistas en ese país en la fecha indicada por el testigo y, peor aún, en Copenhague no existía ningún hotel con ese nombre. c) Por último, otro de los testigos dijo haberse entrevistado en Noruega con Trotsky para recibir de él instrucciones para perpetrar actos 
terroristas; sin embargo, ello resultaba imposible, pues el gobierno noruego tenía confinado a Trotsky en una casa de un poblado lejano y en un lugar bastante inaccesible.

Se trata solo de unos pocos ejemplos de errores de procedimiento, de inexactitudes y de falacias, pero quien lee los dos informes (el que contiene las audiencias de Coyoacán y el elaborado por la Comisión Dewey) encontrará muchísimos más ejemplos de acusaciones falsas, de confesiones malintencionadas y de mentiras evidentes. Es claro, entonces, como bien lo mostró la comisión, que los procesos de Moscú fueron simples montajes judiciales; es decir, que no solo fueron irregulares desde todo punto de vista por sus procedimientos, sino que las confesiones de los testigos fueron totalmente forzadas y que, a pesar de todo ello, la gran mayoría de los acusados fueron condenados y muy buena parte de ellos ejecutados sin que hubiesen tenido ocasión de defenderse.

Lo sorprendente, sin embargo, es que tales procesos siguen siendo reivindicados aún hoy por parte de muchas personas e incluso a veces son presentados, si no como modelos de lo que constituye un juicio justo, al menos como ejemplos del modo como legítimamente un Estado tiene derecho a defenderse contra sus enemigos internos y externos ${ }^{20}$. No quisiera ahora entrar en una polémica con quienes reivindican procesos tan irregulares desde el punto de vista político, jurídico y social. Puesto que analizo este caso desde la perspectiva del papel que la mentira, y específicamente la mentira política, la mentira promovida desde la esfera del poder estatal, tiene en las naciones democráticas, resulta mucho más adecuado analizar a continuación el proceso por el cual se pretendió, en la época misma de los procesos de Moscú y en los años sucesivos, ofrecer una versión oficial y favorable de dichos procesos a través de los medios de comunicación, y particularmente de la prensa y del cine. Allí Dewey tuvo que enfrentar las versiones favorables al régimen soviético fabricadas en su propio país.

20 Para no citar sino un caso de cómo, aún hoy, se pretende reivindicar la legitimidad de estos procesos, véase Bolton, 2011. 
La Comisión Dewey presentó su informe en diciembre de 1937, pero su impacto no fue el deseado ${ }^{21}$. Por el contrario, los mismos que hicieron todo lo posible para que la comisión no se formara, redoblaron sus esfuerzos para desprestigiar sus conclusiones y, sobre todo, para crear una versión de los procesos de Moscú que fuera favorable al régimen de Stalin. Entre tanto, el estalinismo seguía cometiendo los crímenes más horrendos al interior de la Unión Soviética, al tiempo que acusaba a todos sus críticos de partidarios del fascismo mientras, por su parte, Stalin negociaba en secreto con Hitler un pacto de no agresión y extendía sus tentáculos hasta la propia Ciudad de México para, finalmente, dar muerte a Trotsky por medio de un oscuro personaje, Ramón Mercader, el 21 de agosto de 1940.

Ya hicimos antes una breve referencia a las presiones que distintas personas ejercieron sobre Dewey para disuadirlo de que viajara a México como presidente de la subcomisión que recogería el testimonio de Trotsky en la capital azteca. Veremos a continuación la polémica que suscitó varios años después la publicación de una serie de versiones sobre los procesos de Moscú que buscaban justificar a ultranza las acciones del régimen de Stalin. Antes de ello, quisiera

21 De hecho, excepto en algunos sectores de la intelectualidad norteamericana, el caso Trotsky y el informe Dewey terminaron por pasar casi desapercibidos. Unos años después Trotsky sería asesinado por un agente del estalinismo y, aunque periódicamente se busca rehabilitar su figura histórica por parte de militantes trotskistas en todo el mundo, la verdad es que con el tiempo ha terminado por desdibujarse el muy definitivo papel que jugó en la Revolución de Octubre, así como su condición de primer y fundamental crítico del comunismo ortodoxo de carácter estalinista. Tampoco el informe Dewey corrió con mayor suerte: se publicó inicialmente en Harper \& Brothers, de Nueva York, en 1938 y solo se volvió a publicar más de treinta años después, en 1972; la edición más reciente, que es la que he estudiado, es de 2008. Sin embargo, si bien no sé si ha sido traducido a otros idiomas, es claro que no se consigue en español ni siquiera una versión parcial (aunque desde 2010 contamos con una versión en español de las audiencias de Coyoacán). Todo ello es comprensible si se tiene en cuenta, en primer lugar, que ciertamente la situación política en que se dio todo este asunto (los años previos a la Segunda Guerra Mundial) no constituía el ambiente adecuado para que este se conociera más a fondo. No invalida, sin embargo, el hecho de que el caso Trotsky es algo de lo que poco se habla, entre otras cosas porque la actuación en él de muchos Estados, y de muchos movimientos políticos de diversa índole, fue realmente vergonzosa. 
recordar brevemente el modo como la prensa mundial, y especialmente la norteamericana, dio cubrimiento a este asunto.

El caso Trotsky implicó para Dewey, como ya se mencionó, la renuncia al comité editorial de New Republic, uno de los principales órganos de los intelectuales de izquierda norteamericanos, por el modo interesado y la poca objetividad con que allí se venía manejando el asunto. No menos agresiva fue, desde luego, la defensa a ultranza que medios de comunicación vinculados al movimiento comunista, como la revista New Masses, hicieron de los procesos de Moscú. Mientras tanto, periódicos tan importantes como The New York Times, a través de su corresponsal en Moscú, no solo negaba lo que ya todo el mundo empezaba a saber (la hambruna que causaba en la Unión Soviética la colectivización forzada de la agricultura), sino que inventaba argumentaciones falaces para insistir en lo evidente que resultaba la culpabilidad de Trotsky, a quien, además, buscaba asemejar al propio Hitler. Incluso un antiguo alumno de Dewey, Corliss Lamont (el hijo de un famoso banquero devenido luego defensor a ultranza del estalinismo), promovió que se escribiera una carta, firmada por varios intelectuales norteamericanos muy reconocidos, en la que se afirmaba que la crítica a los procesos de Moscú se constituía en una intervención inadmisible en los asuntos internos de la Unión Soviética; y llegó a hacer una réplica pública en un programa de radio, al informe de la Comisión Dewey, en la cual, aunque no refutaba ninguna de sus conclusiones, exaltaba los indudables logros del régimen soviético ${ }^{22}$.

Sin embargo, el más claro intento por fabricar una versión de los procesos de Moscú que fuese grata al régimen soviético vino unos años después, hacia 19411942. Todo empezó con la publicación, por parte de Joseph Davies, el embajador del gobierno norteamericano de F. D. Roosevelt en la Unión Soviética en la época de los procesos de Moscú, del libro Misión en Moscú (Mission to Moscow). En él Davies (1941), después de una curiosa "revelación" que tuvo lugar varios años después de su misión diplomática, llegó a la conclusión de que dichos procesos eran completamente legítimos; y que no se había dicho nada allí que fuese mentira ni se había hecho nada que fuese injusto. El libro tuvo amplia difusión y fue muy bien recibido por el público lector. El único que se opuso a esta fabricación

22 La reacción de la prensa norteamericana ante los procesos de Moscú y el informe de la Comisión Dewey se describe con detalle y precisión en Hook, 1984. 
de la verdad fue John Dewey, que escribió en el New York Times y en New Leader denunciando las muchas falsedades allí contenidas.

Pero tampoco allí pararon las cosas. Poco tiempo después, la propia industria cinematográfica de Hollywood convirtió el libro de Davies en una película del mismo nombre, que comenzaba con el propio embajador prometiendo a los espectadores que les contaría la verdad de lo ocurrido en la Unión Soviética, pues solo él la conocía como testigo privilegiado ${ }^{23}$. De nuevo, fue Dewey quien mostró las falsedades, contradicciones y ambigüedades de la producción hollywoodense. Detengámonos brevemente en la crítica que hace Dewey tanto al libro de Davies como a la película que él inspira, pues allí el filósofo norteamericano da cuenta de algunas de las estrategias más comunes de ocultamiento de la verdad y de creación de una versión de los acontecimientos favorable a un régimen político por parte de los medios de comunicación.

El libro Misión en Moscú, de Joseph Davies, fue publicado en 1941 en Nueva York por Simon and Schuster, y su publicación tuvo un éxito modesto, puesto que se ocupaba de un tema que despertaba por entonces mucha controversia: lo que venía ocurriendo en la Unión Soviética por esos años. Buena parte de la crítica, además, lo recibió con beneplácito. Dewey, que había leído con cuidado el libro, preparó dos documentos sobre él. Por una parte, escribió una carta al editor de The New York Times para advertirle que, a pesar de que las reseñas que se habían hecho en su periódico sobre el libro de Davies eran muy favorables, él tenía objeciones de fondo que hacer a la perspectiva sobre la Unión Soviética allí ofrecida por el exembajador norteamericano. Por otro lado, Dewey escribió una reseña, un poco más elaborada y crítica, para New Leader. En este segundo texto cuestionaba de un modo radical la versión de Davies sobre lo que ocurría en Rusia y, sobre todo, el hecho de que toda su visión de la URSS hubiese sido el fruto de una "revelación" que el autor tuvo tres años después de su regreso a los Estados Unidos ("Mission to Moscow Reveals No New Evidence on Soviet Trials", en: Dewey, $L W 15$, pp. 289-294). Sin embargo, me ocuparé más del primero de estos textos, pues allí Dewey es más contundente con respecto a su apreciación

23 La película, dirigida por Michael Curtiz y basada por entero en el libro de Davies, fue estrenada a comienzos de 1943. La película completa, con subtítulos en español, puede verse en el siguiente vínculo: https://vimeo.com/182767468 
de lo que fue presentado por el exembajador como una vulgar falsificación de los hechos que resulta favorable al régimen estalinista. Cito algunos pasajes de la carta en mención, publicada bajo el nombre "Russia’s Position. Mr. Davies's Book Regarded as Incorrect Picture":

El señor Davies comparte la perspectiva oficial soviética según la cual el terror de Stalin -del cual los tres grandes procesos de Moscú y la ejecución de los altos comandantes del Ejército Rojo fueron los eventos más sobresalientes- era una forma de librarse de los agentes de Hitler en la Unión Soviética. [...] Parece que también se tragó, sin que por ello se sintiera amordazado, la ejecución de los generales sin que mediara proceso público alguno. $\mathrm{Y}$ algo semejante hizo en el posterior proceso Bukharin-Rykov de enero de 1938, en el cual, como él mismo lo indica en una casual nota de pie de página, "se levantaron por primera vez cargos detallados y específicos contra el Ejército Rojo en los que se implicaba a algunos de sus líderes en actividades de 'quinta columna'”. No había ninguna prueba detallada y específica, pero iclaro!, bastaba con que hubiera "cargos" de ese tenor para que, en retrospectiva, le pareciera al señor Davies que estaba justificada la creencia de que los generales eran culpables.

[...] No sé si hubo o no hubo quintacolumnistas en Rusia. Tampoco sé si había quintacolumnistas entre los acusados en los procesos de Moscú. Lo que sí sé, y lo sé después de un cuidadoso estudio de los informes de los procesos, es que es imposible encontrar alguna evidencia creíble de una actividad de quintacolumna en medio de las contradicciones, confusiones y patentes mentiras de los acusados, los testigos autoinculpados y el fiscal de dichos procesos. Puedo decir esto aun sin tomar en cuenta mentiras tan atroces y tan puntualmente expuestas como el famoso testimonio acerca de un inexistente "Hotel Bristol" o la de aquel supuesto viaje aéreo secreto de Pyatakov a Oslo en mitad del invierno. Sé también que cualquier persona desinteresada que se ocupara del problema y que estudiara efectivamente los informes -que están disponibles en traducciones oficiales al inglés publicadas por el propio gobierno soviético- debería llegar inevitablemente a la misma conclusión.

O el señor Davies desconoce las implicaciones políticas de dichos procesos o simplemente decide pasarlas por alto. A pesar de ello, hace esta significativa 
observación en su informe sobre la ejecución de los generales: "el régimen de Stalin, tanto política como internamente, es probablemente más fuerte que cualquiera otro que haya existido hasta el momento. Toda potencial oposición ha sido eliminada”.

Si uno examina los procesos a la luz de esta observación del señor Davies, de allí emerge una muy diferente imagen de aquella que él ha elegido ver. Lo que surge es precisamente la imagen de un dictador totalitario que está consolidando su poder por medio de la eliminación de "toda potencial oposición”. Pues, ¿qué otros probables focos de oposición podrían haber existido en Rusia que los socios de Lenin, y los héroes de la revolución y la guerra civil, que aún sobrevivían y que fueron precisamente los acusados principales de los procesos de Moscú? (Dewey, $L W$ 15, pp. 338-339; traducción propia).

Por supuesto, la carta de Dewey es más larga y se ocupa de otros asuntos de política internacional, especialmente del papel que en el momento cumplió Stalin en la geopolítica mundial (es un texto de 1942, escrito en plena Segunda Guerra Mundial). Pero lo que, sobre todo, quiso poner de presente fue que la versión inventada por Davies solo era comprensible a la luz de su propia relación de cordialidad con el régimen estalinista, pues aun sus críticas al régimen soviético - y las hay en su obra- solo servían para dar una pretensiosa objetividad a su versión de los acontecimientos. Dewey había estudiado los procesos de Moscú, había leído todos los documentos y escuchado directamente el testimonio del principal de los acusados, y no estaba dispuesto por ello a aceptar una versión tan complaciente de un hecho histórico de esa magnitud.

Que se trata de una versión de los procesos de Moscú políticamente interesada resulta más claro todavía cuando a partir del libro de Davies se realizó una película con el mismo título. Dewey no tuvo problema en volver a denunciarlo ante la opinión pública. En una carta escrita junto con Suzanne La Follette, la secretaria de la Comisión Dewey y redactora de su informe, y publicada en la página 8 del New York Times del 9 de mayo de 1943 ("Several Faults Are Found in Mission to Moscow Film"), empezaron por decirlo de forma expresa y sin ambages:

La película Misión en Moscú es el primer ejemplo en nuestro país de propaganda totalitaria para el consumo de las masas, una propaganda que falsifica 
la historia a través de la distorsión, la omisión o la simple invención de hechos y cuyo efecto solo puede ser confundir al público tanto en su pensamiento como en sus lealtades.

Incluso si se tratara de una película de ficción, el método utilizado resultaría perturbador. Se convierte en alarmante que, en una película que se presenta como referida a hechos y como documentada, se introduzcan personalidades históricas vivientes: nuestro anterior Embajador en la Unión Soviética, Joseph Davies, introduce personalmente la dramatización de su misión, a la que presenta como "la verdad" sobre Rusia; y la representación posterior del Presidente Roosevelt hablando con el señor Davies de la película parece sugerir que esta es al menos semioficial (Dewey, $L W 15$, p. 345; traducción propia).

Viene a continuación un análisis detallado de los distintos aspectos de la historia soviética, las relaciones internacionales y la propia historia norteamericana que la película distorsiona. Para Dewey y La Follete es claro que una película es una obra de arte y que, por tanto, no se debe esperar que en ella todo sea verificable, pues necesariamente tiene algo de ficción. Sin embargo, tratándose de una película que se hace con base en un libro que ha prometido contar "la verdad acerca de Rusia" (promesa que se renueva al comienzo del filme), no es posible aceptar las muchas distorsiones que contiene y que fácilmente pueden pasar por alto quienes no conocen a fondo los hechos históricos.

Sin afán de ser exhaustivo, he aquí una pequeña lista de algunas de las principales falsificaciones, contradicciones e imposibilidades en que incurre la película tal cual la analizan Dewey y La Follette. Aunque se ocupa de los procesos de Moscú, no los sitúa en el contexto más amplio de las purgas de la era estalinista; empieza por una escena en donde el embajador participa de una recepción diplomática en su honor, en la que aparecen muchos líderes de la Revolución (a los cuales ni siquiera se hace referencia en el libro) que ya por entonces se encontraban procesados o en la cárcel, algo que constituye al menos una inexactitud histórica. Presenta como uno de los acusados al mariscal Tukhachevsky, quien no fue juzgado, sino simplemente ejecutado secretamente en junio de 1937. La película deja la impresión de que Stalin no estaba deshaciéndose de potenciales opositores políticos (todos ellos considerados por mucho tiempo como héroes de la Revolución), sino de traidores al servicio de poderes extranjeros, etc. 
No incluyo aquí otra serie de críticas que hacen Dewey y La Follette a la versión que presenta la película de muchos asuntos de la geopolítica internacional, como las actuaciones de Alemania y la URSS en la guerra, la política británica o cierta crítica del sistema parlamentario que resulta sospechosa.

La película es, para resumir -concluyen los autores de la carta-, antibritánica, anticongreso, antidemocrática y antiverdad. Ella profundiza esa crisis en la moral que constituye el problema fundamental del mundo moderno. La película Misión en Moscú, y la propaganda similar, han ayudado a crear una cierta insensibilidad moral en nuestra mentalidad pública que resulta profundamente antinorteamericana. Hace poco el pueblo norteamericano recibió con comparativa calma el anuncio del gobierno soviético de que había ejecutado como "agentes nazis" a dos judíos polacos, Ehrlich y Alter, internacionalmente conocidos como líderes de los obreros socialistas que habían sido arrestados cuando ellos invadieron Polonia. Unas pocas películas más que sean aceptadas de forma tan acrítica como ha sido aceptada esta -pues, mientras son miles los que leen libros, son millones los que ven películas- y los norteamericanos se volverán insensibles a todos los valores morales.

Misión en Moscú es una derrota mayor para la causa democrática. Al hacer esta película los productores, lejos de prestar el servicio patriótico por el que les agradece el señor Davies, han asaltado los verdaderos fundamentos de la libertad, pues la verdad y la libertad son indivisibles, como bien lo sabía Hitler cuando expuso su método de confusión de la opinión pública por medio de la propaganda. Esta película hace un uso muy eficiente de la técnica hitleriana (Dewey, $L W 15$, pp. 349-350; traducción propia).

La polémica, por supuesto, no terminó aquí. Por el contrario, se extendió por un tiempo más, precisamente en la medida en que siguieron existiendo interesados en mantener una versión de lo que ocurrió en los procesos de Moscú, y en los tiempos de la dictadura estalinista, que resultara favorable al régimen ${ }^{24}$. Pero, como de costumbre, en la guerra el primer perdedor es la verdad. Lo que

24 Dewey mantuvo una polémica con Arthur Upham Pope sobre la película en mención, que se puede seguir en el volumen 15 de los Later Works de John Dewey, pero de la que no nos ocuparemos aquí. 
ocurrió en los procesos de Moscú, la brutal persecución del Estado soviético contra Trotsky y la propia investigación de la Comisión Dewey quedaron prácticamente en el olvido con la llegada de la Segunda Guerra Mundial y, luego, de la llamada Guerra Fría ${ }^{25}$. Y, como siempre, nuevas guerras traen nuevas mentiras. Muchos se ilusionaron con la idea de que, con las denuncias de los crímenes del estalinismo hechas por Nikita Khrushchev en el Vigésimo Congreso del Partido Comunista de la URSS, en 1956, se recuperaría por fin la memoria de tan espantosos sucesos como fueron las purgas estalinistas y ese sainete judicial conocido como los procesos de Moscú. Pero nunca ocurrió tal cosa. Nunca se examinaron de nuevo. No lo hizo Khrushchev y no lo ha hecho ninguno de sus sucesores. Y, aunque muchos de quienes defendieron a ultranza al estalinismo hoy estarían dispuestos a calificarlo de totalitarista, siempre habrá quienes, por un oscuro afán de poder, están dispuestos a recurrir a la mentira, al engaño y a la falsificación con tal de obtener un poder que aún no tienen o de aferrarse locamente a un poder que ya poseen.

En 1934, unos años antes de que se inmiscuyera en este asunto, John Dewey se había preguntado por qué no era, ni le era posible ser, comunista en el sentido oficial y ortodoxo, estalinista, que la palabra "comunista" tenía por aquella época. Una de las razones de fondo para ello era el desprecio que el comunismo oficial tenía por la verdad, la deliberación reflexiva y la libre investigación. Decía en aquel momento, en "Why I Am Not a Communist":

[...] una de las razones por las cuales no soy comunista es porque el tono emocional y los métodos de discusión y disputa que parecen acompañar al comunismo en la actualidad resultan extremadamente repugnantes para mí. El juego limpio y una elemental honestidad en la presentación de los hechos, y especialmente de las opiniones de otros, son algo más que meras "virtudes burguesas"; son cualidades que se han ganado solamente a través de una prolongada lucha. No son cosas que estén profundamente arraigadas en la naturaleza humana, y mucho menos ahora; de ello dan testimonio los métodos por medio de los cuales accedió el hitlerismo al poder. El desprecio sistemático, persistente y aparentemente intencional de estos asuntos por parte de los

25 La denuncia que hizo Natalia Sedova en los juicios de Nuremberg fue desatendida. 
voceros del comunismo en el discurso público y en la prensa, la histeria de sus denuncias, sus intentos por difamar a sus oponentes, su presentación falaz de los puntos de vista de los "liberales" (a quienes también apelan, cuando lo requieren, en apoyo para sus campañas), su política de "regla o ruina” en sus llamadas actividades de frente unido, su aparente convicción de que lo que ellos consideran como un fin justifica el uso de cualquier medio simplemente porque este medio promete ser exitoso; todas estas cosas, a mi juicio, son fatales para el verdadero fin que los comunistas oficiales dicen albergar en su corazón (Dewey, $L W 9$, p. 94; traducción propia).

Su participación en el caso Trotsky, su ejercicio investigativo con respecto a los procesos de Moscú y la lucha contra la falsificación de los acontecimientos por parte de los medios masivos de comunicación de su época (la prensa y el cine) parecen haber incrementado en Dewey su convicción de que la verdad es un bien social que una democracia debe proteger en contra de todos los que están dispuestos a falsear lo realmente ocurrido, con tal de que sirva a sus mezquinos intereses económicos y de poder. En su último pronunciamiento sobre el caso Trotsky, en una entrevista con Agnes Meyer publicada en las páginas 3 y 4 del Washington Post del 19 de diciembre de 1937, contaba lo que fue su experiencia personal en la URSS y lo mucho que lamentaba que un pueblo trabajador y creativo como el ruso se encontrara sometido por una casta burocrática, que seguía afirmando que la verdad no es más que una "virtud burguesa” que conviene desechar. Atendamos a su testimonio, recogido en "Significance of the Trotsky Inquiry":

Las revelaciones que hemos tenido acerca de la Unión Soviética en el último tiempo han sido, para mí personalmente, amargas y desilusionantes. Siempre sentí que las tradiciones rusas y las de nuestro país eran tan disímiles entre sí que no podrían compararse literalmente las unas con las otras; creía, sin embargo, que un experimento social de la más alta importancia estaba desarrollándose en ese país, un experimento del cual nosotros, y las demás naciones llamadas capitalistas, podríamos aprender muchísimo. Veía a la Unión Soviética como un laboratorio social en el cual se pondrían en práctica experimentos significativos. Antes de la época de la depresión económica -es decir, mucho antes de que cambiara la perspectiva para muchos de nuestros 
jóvenes intelectuales-, en 1928, para ser exactos, visité la Unión Soviética; y, a mi retorno, escribí una serie de artículos en los cuales presentaba aspectos favorables de lo que habían conseguido allí en los campos educativo y cultural. Por aquello fui denunciado luego como Rojo y Bolchevique.

He dedicado mi vida al estudio de lo que ocurre en las escuelas, que fueron hechas para el desarrollo de la gente joven y para la propagación de la cultura entre las masas, mientras que no he realizado ningún estudio sobre las condiciones económicas. A pesar de la indebida prevalencia de la propaganda en las escuelas, quedé auténticamente impresionado por la esperanza de la gente joven y, al mismo tiempo, por su actitud relativamente libre. Aunque no hice examen ninguno de las condiciones políticas, no era entonces consciente de cuán imposible resultaba para cualquier viajero o turista adentrarse en los detalles, cualesquiera que ellos fueran, a través de medios políticos.

Todo esto fue antes de la iniciación del primer plan quinquenal. Todas las cosas se hicieron más estrictas bajo la presión de dicho plan; sin embargo, no tengo duda ahora de que las causas de las cada vez mayores restricciones políticas que llevaron finalmente al establecimiento de un reino del terror ya venían funcionando desde entonces. Naturalmente tales causas habían afectado ya todo el sistema educativo. La propaganda y la disciplina rígida habían crecido enormemente; y ello a tal punto que ahora los alumnos ya portaban uniformes. Los gérmenes de libertad educativa que ciertamente existían en las mejores escuelas por aquella época ya habían sido, de acuerdo con informes confiables, completamente destruidos.

He aprendido a tener un gran respeto por las capacidades de la gente rusa y, pesar del oscuro horizonte actual, aún me considero incapaz de renunciar a dicha fe. Me resulta, sin embargo, imposible concebir cómo es que se puede lograr la transformación social bajo las condiciones presentes de supresión de la individualidad, falsificación y terrorismo. Un pueblo al que se le conserva sistemáticamente en la ignorancia sobre lo que está ocurriendo en el mundo, y en su propio país, y al que se le alimenta con mentiras, ha perdido la fuerza motivacional para el progreso. Para mí, como educador, lo que está ocurriendo hoy en Rusia es una gran tragedia. 
Me resulta igualmente descorazonador que en nuestro país algunos que se dicen liberales terminen creyendo que, por razones de conveniencia para nuestra propia gente, deberíamos permanecer en la oscuridad con respecto a la actual situación rusa. Pues la verdad, en vez de ser una virtud burguesa, es el móvil por excelencia del progreso humano (Dewey, $L W 11$, pp. 335-336; traducción propia).

\section{Referencias}

Bernstein, R. (2012). Dewey's Encounter with Trotsky. Inter-American Journal of Philosophy, 3(2), 5-15.

Bolton, K. R. (2011, abril 22). The Moscow Trials in Historical Context. Foreign Policy Journal. Recuperado de: https://www.foreignpolicyjournal. com/2011/04/22/the-moscow-trials-in-historical-context/

Brickman, W. (1966). Actitudes del Estado soviético hacia John Dewey considerado como educador. En: D. Lawson \& A. Lean (Comps.). John Dewey. Visión e influencia de un pedagogo (pp. 99-210). Buenos Aires: Nova.

Comisión Dewey (2010). El caso León Trotsky. Informe de las audiencias sobre los cargos hechos en su contra en los procesos de Moscú (Trad. C. Murillo et al.). Buenos Aires: Ediciones IPS.

Davidson, J. (2016). El asesino obediente. Ramón Mercader y la muerte de Trotsky. Barcelona: Plaza y Janés.

Davies, J. (1941). Mission to Moscow. A record of confidential dispatches to the State Department, official and personal correspondence, current diary and journal entries, including notes and comment up to October, 1941. New York: Simon and Schuster. [Hay versión en español: Davies, J. (1942): Misión en Moscú. (Trad. I. Covarrubias). Buenos Aires: Librería Marcos Sastre.

Dewey, J. (1986). Why I am Not a Communist. En: J. A. Boydston (Ed.). The Later Works of John Dewey 1925-1953 (Vol. 9) (pp. 91-95). Carbondale y Edwardsville: Southern Illinois University Press.

Dewey, J. (1987). Declaration of Purposes by the American Committee for the Defense of Leon Trotsky. En: J. A. Boydston (Ed.). The Later Works of John Dewey 1925-1953 (Vol. 11) (pp. 303-305). Carbondale y Edwardsville: Southern Illinois University Press. 
Dewey, J. (1987). Introductory Statement of the Commission of Inquiry. En: J. A. Boydston (Ed.). The Later Works of John Dewey 1925-1953 (Vol. 11) (pp. 306-309). Carbondale y Edwardsville: Southern Illinois University Press.

Dewey, J. (1987). Significance of the Trotsky Inquiry. En: J. A. Boydston (Ed.). The Later Works of John Dewey 1925-1953 (Vol. 11) (pp. 330-336). Carbondale y Edwardsville: Southern Illinois University Press.

Dewey, J. (1987). Summary of Findings. En: J. A. Boydston (Ed.). The Later Works of John Dewey 1925-1953 (Vol. 11) (pp. 321-325). Carbondale y Edwardsville: Southern Illinois University Press.

Dewey, J. (1987). The Leon Trotsky Inquiry. En: J. A. Boydston (Ed.). The Later Works of John Dewey 1925-1953 (Vol. 11) (pp. 303-336). Carbondale y Edwardsville: Southern Illinois University Press.

Dewey, J. (1987). The Moscow Trials. En: J. A. Boydston (Ed.). The Later Works of John Dewey 1925-1953 (Vol. 11) (pp. 326-329). Carbondale y Edwardsville: Southern Illinois University Press.

Dewey, J. (1987). Truth Is on the March. En: J. A. Boydston (Ed.). The Later Works of John Dewey 1925-1953 (Vol. 11) (pp. 310-320). Carbondale y Edwardsville: Southern Illinois University Press.

Dewey, J. (1988). In Defense of the Mexican Hearings. En: J. A. Boydston (Ed.). The Later Works of John Dewey 1925-1953 (Vol. 13) (pp. 347-348). Carbondale y Edwardsville: Southern Illinois University Press.

Dewey, J. (1989). Dr. Dewey on Our Relations with Russia. En: J. A. Boydston (Ed.). The Later Works of John Dewey 1925-1953 (Vol. 15) (pp. 342-344). Carbondale y Edwardsville: Southern Illinois University Press.

Dewey, J. (1989). Mission to Moscow Reveals No New Evidence on Soviet Trials. En: J. A. Boydston (Ed.). The Later Works of John Dewey 1925-1953 (Vol. 15) (pp. 289-294). Carbondale y Edwardsville: Southern Illinois University Press.

Dewey, J. (1989). More on Mission to Moscow. En: J. A. Boydston (Ed.). The Later Works of John Dewey 1925-1953 (Vol. 15) (pp. 354-355). Carbondale y Edwardsville: Southern Illinois University Press.

Dewey, J. (1989). Moscow Film Again Attacked. Miss La Follette and Dr. Dewey Reply to Mr. Pope's Arguments. En: J. A. Boydston (Ed.). The Later Works of 
John Dewey 1925-1953 (Vol. 15) (pp. 351-353). Carbondale y Edwardsville: Southern Illinois University Press.

Dewey, J. (1989). Russia's Position. Mr. Davies's Book Regarded as Incorrect Picture. En: J. A. Boydston (Ed.). The Later Works of John Dewey 1925-1953 (Vol. 15) (pp. 338-341). Carbondale y Edwardsville: Southern Illinois University Press.

Dewey, J. (1989). Several Faults Are Found in Mission to Moscow Film. En: J. A. Boydston (Ed.). The Later Works of John Dewey 1925-1953 (Vol. 15) (pp. 345-350). Carbondale y Edwardsville: Southern Illinois University Press.

Dewey, J., \& Kallen, H. (1988). Statement by the American Committee for the Defense of Leon Trotsky. En: J. A. Boydston (Ed.). The Later Works of John Dewey 1925-1953 (Vol. 11) (pp. 598-599). Carbondale y Edwardsville: Southern Illinois University Press.

Dewey Commission (2008). Not Guilty. Findings of the 1937 Commission Chaired by John Dewey Investigating the Charges against Leon Trotsky in the Moscow Trials. New York: Pathfinder.

Farrell, J. (1950). Dewey in Mexico. En: S. Hook (Ed.), John Dewey: Philosopher of Science \& Freedom. A Symposium (pp. 351-377). New York: The Dial Press.

Hook, S. (1984, marzo). Memories of the Moscow Trials. Commentary. Recuperado de: https://www.commentarymagazine.com/articles/memories-ofthe-moscow-trials/

Kraus, K. (1990). Moralidad y criminalidad. En: J. L. Arántegui (Ed.). Escritos (pp. 15-27). Madrid: Visor.

Luri, G. (2016). El cielo prometido: una mujer al servicio de Stalin. La bistoria de la familia Mercader. Bogotá: Planeta.

Novack, G. (2010). Introducción. En: Comisión Dewey. El caso León Trotsky. Informe de las audiencias sobre los cargos hechos en su contra en los procesos de Moscú (pp. 29-34). Buenos Aires: Ediciones IPS.

Padura, L. (2009). El hombre que amaba los perros. Barcelona: Tusquets.

Reissner, W. (2008). Introduction. En: Dewey Commission. Not Guilty. Findings of the 1937 Commission Chaired by John Dewey Investigating the Charges against Leon Trotsky in the Moscow Trials (pp.7-14). New York: Pathfinder. 
Roche, G. (2010). Los intelectuales norteamericanos y la Comisión Dewey. (Trad. R. Cortez). Cuadernos del CEIP, 14. Recuperado de: http://www. ceip.org.ar/Boletin-No-14-Edicion-impresa-Noviembre-2010

Steiner, G. (2003). Trotsky y la imaginación trágica. En: Lenguaje y silencio. Ensayos sobre la literatura, el lenguaje y lo inbumano (pp. 410-418) (Trad. M. Ultorio). Barcelona: Gedisa. 